\title{
Illustrated keys to Scoliidae (Insecta, Hymenoptera, Scolioidea) from China
}

\author{
Zhen Liu', Cornelis Van Achterberg'2 Jun-Hua $\mathrm{He}^{2}$, \\ Xue-Xin Chen ${ }^{2}$, Hua-Yan Chen ${ }^{3}$
}

I College of Life and Environmental Sciences, Hunan University of Arts and Science, Changde 415000, China 2 State Key Lab of Rice Biology, Ministry of Agriculture Key Lab of Molecular Biology of Crop Pathogens and Insects, Institute of Insect Sciences, Zhejiang University, Hangzhou 310058, China 3 State Key Laboratory of Biocontrol, School of Life Sciences / School of Ecology, Sun Yat-sen University, Guangzhou 510275, China

Corresponding authors: Zhen Liu (qingniao8.27@163.com); Cornelis Van Achterberg (kees@vanachterberg.org)

Academic editor: A. Köhler | Received 26 November 2020 | Accepted 22 February 2021 | Published 22 March 2021

http://zoobank.org/F530AA74-3DB6-4375-8759-DEA3D5E28B22

Citation: Liu Z, Van Achterberg C, He J-H, Chen X-X, Chen H-Y (2021) Illustrated keys to Scoliidae (Insecta, Hymenoptera, Scolioidea) from China. ZooKeys 1025: 139-175. https://doi.org/10.3897/zookeys.1025.61385

\begin{abstract}
The Scoliidae occur predominantly in tropical and subtropical regions and are ectoparasitoids of Scarabaeoidea larvae (especially of Melolonthinae) which are immobilised, parasitised by the female wasp in their terrestrial larval gallery and buried deeper in a special cell by the female wasp. Herein, we provided, for the first time, illustrated keys to 11 genera and 52 species of Scoliidae from China, based on specimens in the Naturalis Biodiversity Center (RMNH, Leiden) and additional specimens from the Chinese Academy of Insect Science (Beijing), Zhejiang University (ZJUH, Hangzhou) and Sun Yat-sen University (SYSU, Guangzhou) and it is a first attempt to make keys available for all the Scoliidae species in China.
\end{abstract}

\section{Keywords}

China, illustrated keys, Scoliidae

Copyright Zhen Liu et al. This is an open access article distributed under the terms of the Creative Commons Attribution License (CC BY 4.0), which permits unrestricted use, distribution, and reproduction in any medium, provided the original author and source are credited. 


\section{Introduction}

Scoliid wasps (Hymenoptera, Scoliidae) form a medium-sized family with approx. 560 species worldwide and occur predominantly in tropical and subtropical regions (Osten 2005). Scoliidae parasitise exclusively second and third instar beetle larvae of Scarabaeoidea (Illingworth 1919, 1921). There are few studies on this group from China, though several species are common in south and central China. Fabricius (17811804) described 41 species of Scoliidae, including six from China. In the $18^{\text {th }}$ century, more than 20 species have been reported from China by several authors (Lepeletier 1845; Eversmann 1846, 1849; Smith 1855; de Saussure 1858; de Saussure et al. 1864; Morawitz 1889; Bingham 1896, 1897). In the 19 ${ }^{\text {th }}$ century, Betrem (1928) published a monograph on the Indo-Australian Scoliidae, including 72 species and subspecies, of which 20 were reported from China. Later, Betrem (1941) published a systematic study on the Chinese Scoliidae including 2 genera, 61 species, subspecies and varieties from China, which is the first overview of the Chinese fauna, but partly confusing, because of naming too many (overlapping) subspecies and varieties. The systematics is in a state of confusion, which is well summarised by Elliott (2011). In China, 52 species are known (Liu et al., submitted), all belonging to the subfamily Scoliinae. For the present key, we examined Chinese specimens of four major collections: Naturalis Biodiversity Center (RMNH, Leiden, Netherlands), Chinese Academy of Insect science (IOZ, Beijing, China), Zhejiang University (ZJUH, Hangzhou, China) and Sun Yat-sen University (SYSU, Guangzhou, China). In this paper, we provide illustrated keys for all taxa of Scoliidae from China for the first time. This paper is part of an ongoing project on the revision of the Chinese Scoliidae.

\section{Material and methods}

This work is based on specimens in the collections of the Naturalis Biodiversity Center (RMNH), Chinese Academy of Insect Science (IOZ), Zhejiang University (ZJUH) and Sun Yat-sen University (SYSU).

Examination and measurements were made using a stereomicroscope (Zeiss Stereo Discovery V8). Detailed images of specimens were taken and processed using a digital camera Zeiss Stereo Discovery V12 and with the software Axiovision SE64 Rel.49.1. Habitus images were taken with a Nikon D600 camera coupled with a Nikon $60 \mathrm{~mm}$ Macro lens and processed with the software Combine ZM. All images were further processed using Adobe Photoshop CS5. Morphological terms for body structures and measurements followed Betrem et al. (1972). Wing venation nomenclature followed a modified version of the Comstock-Needham (van Achterberg 1979) and Betrem et al. (1972) system. Abbreviations used are as follows: $\mathrm{POL}=$ postocellar line, $\mathrm{OOL}=$ ocular-ocellar line, $\mathrm{OD}=$ ocellar diameter; $\mathrm{T} 1-\mathrm{T} 6=1^{\text {st }}$ to $6^{\text {th }}$ tergite of metasoma; $\mathrm{S} 1-\mathrm{S} 5=1^{\text {st }}$ to $5^{\text {th }}$ sternite of metasoma.

The genitalia were removed, cleaned and pinned under the specimen in a genitalia tube as described by Prosvirov and Savitsky (2011). 


\section{Key to genera of the Scoliidae from China}

1 Second recurrent vein $(2 \mathrm{~m}-\mathrm{cu})$ of fore wing present and connected to second submarginal cell, resulting in two discal cells (a), if rarely absent (aa), then length of body 5-15 mm; mesopleural crest low, often carina-like, directed approximately to posterior corner of pronotum and with a small horizontal area at upper corner (b); T2 and T3 often with subapical row of setae bearing punctures (c); volsella of males divided into two parts (d); basal elevation of S3 ("gradulus") or of T3 usually present (e); Campsomerini. . .2
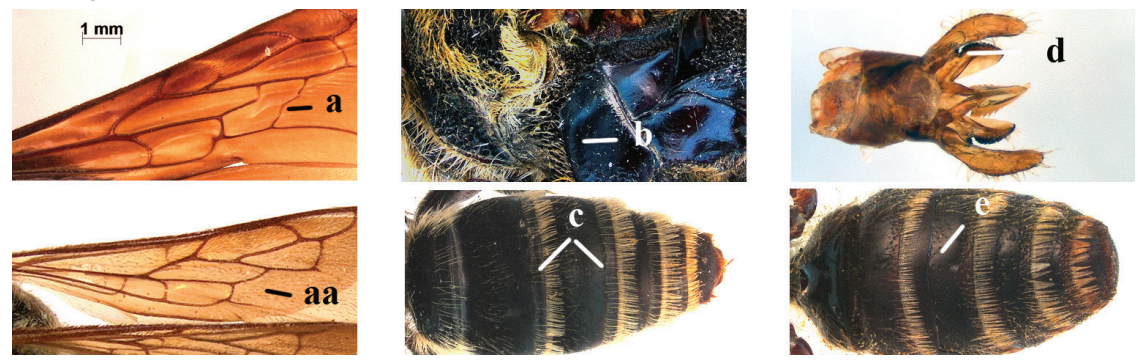

Second recurrent vein $(2 \mathrm{~m}-\mathrm{cu})$ of fore wing absent, resulting in one discal cell (aa) and length of body more than $15 \mathrm{~mm}$ or vein $2 \mathrm{~m}$-cu short and connected to first recurrent vein $(1 \mathrm{~m}-\mathrm{cu})$, thus resulting in a shorter second discal cell (aaa); mesopleural crest high, directed to the base of fore wing and with a large horizontal area (bb); T2 and T3 without subapical row of setae bearing punctures (cc); volsella of males not divided (dd); basal elevation of S3 or of T3 usually absent (ee); Scoliini
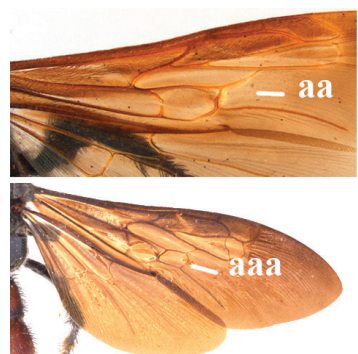
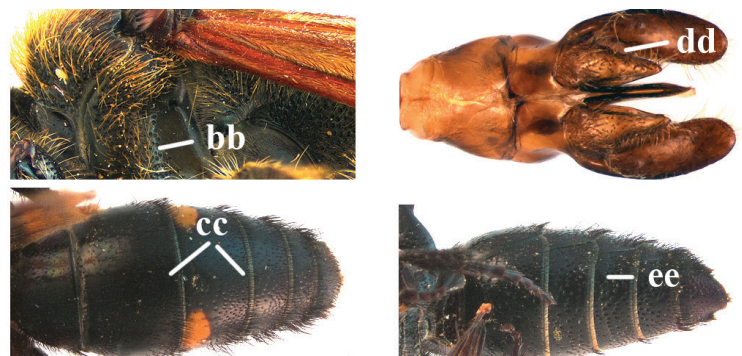

Fore wing with 3 submarginal cells (a); T1-T4 often without subposterior transverse setose bands (b); hypostomal carina of male bisected, with submandibular triangle (c); ventral mandibular furrow of female exposed in frontal view (d); ["Trielidini/Colpinae auct."; in China C. tartara (de Saussure, 1880)]

Colpa Dufour
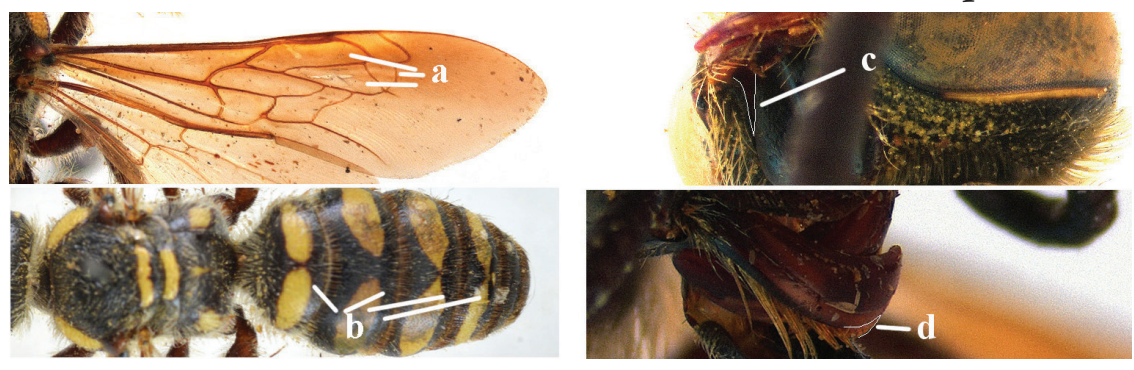
- $\quad$ Fore wing with 2 submarginal cells (aa); T1-T4 often with subposterior transverse setose bands (bb); hypostomal carina of male simple, without submandibular triangle (cc); ventral mandibular furrow of female concealed in frontal view (dd)
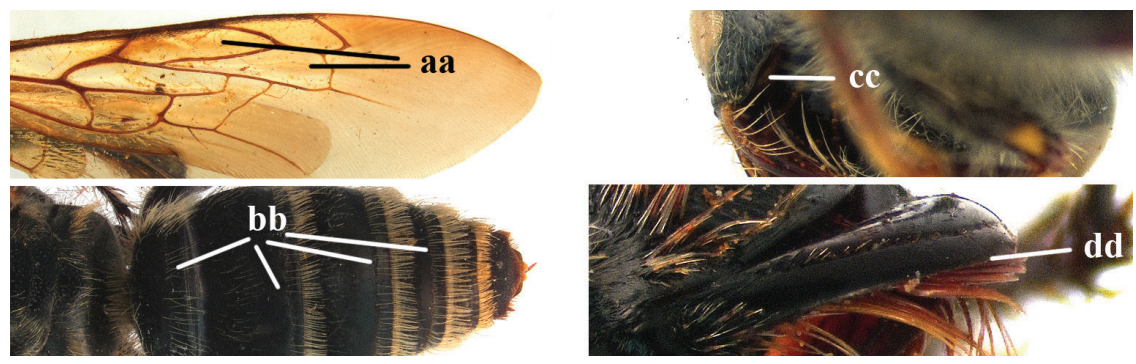

Females (antenna with 12 segments) 4

Males (antenna with 13 segments)

Length of body 9-15 mm; base of hind wing without any carina below and upper plate of metapleuron smooth dorsally (a); metasomal tergites entirely black (b); metasomal setae white, except on apical tergite (c); wings subhyaline to pale brown (d)

Micromeriella Betrem
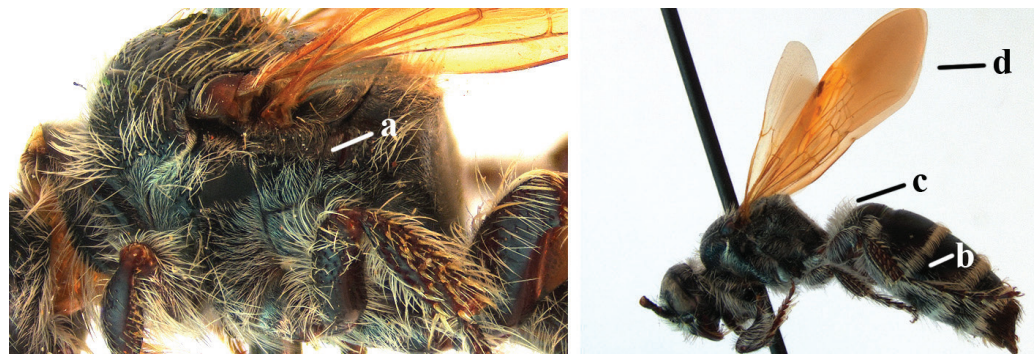

- $\quad$ Length of body $15-35 \mathrm{~mm}$; base of hind wing with a carina below (aa) or upper plate of metapleuron more or less punctate dorsally, transition between its vertical and dorsal areas straight, with or without a carina below base of hind wing (aaa); metasomal tergites entirely black or with yellow or red pattern (bb); metasomal setae often differing in colour from the tegument (cc); wings subhyaline to dark brown $(\mathrm{dd})$.....
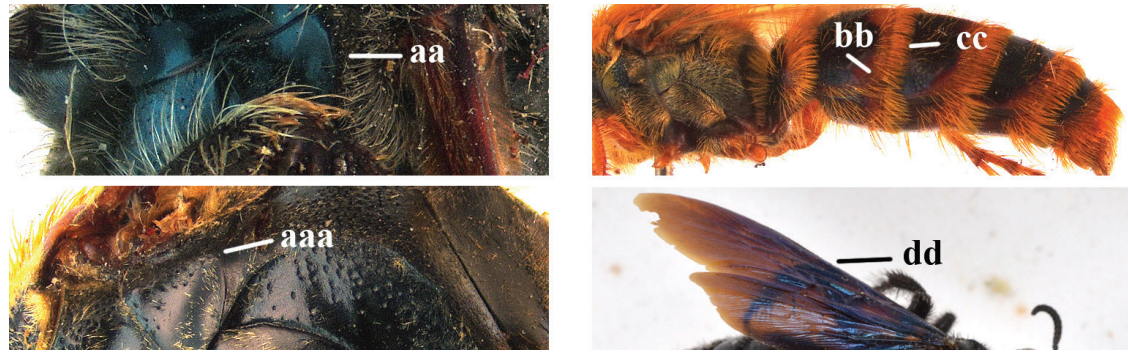
5 Upper plate of metapleuron smooth, sometimes with fine, sparse punctures dorsally, transition between its vertical and dorsal areas straight and with an entirely or partially distinct carina below base of hind wing (a) ...................6 - $\quad$ Upper plate of metapleuron punctate dorsally, transition between its vertical and dorsal areas usually straight anteriorly and gradually sloping posteriorly and without a distinct carina below base of hind wing (aa)
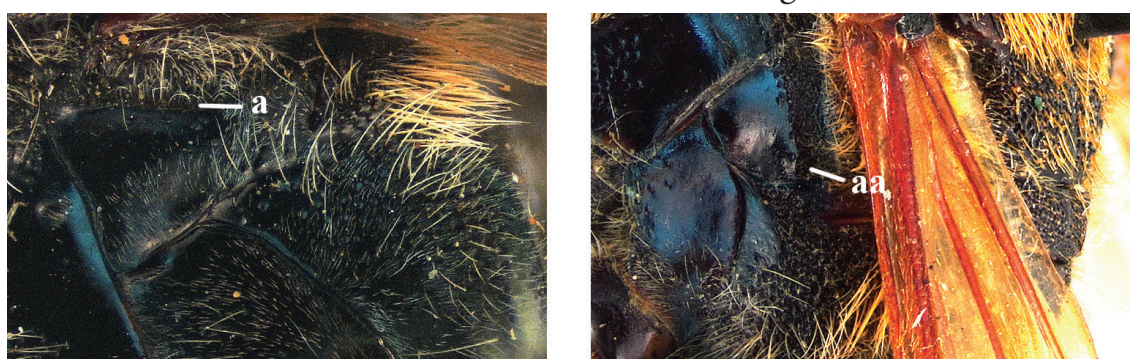

Lateral carina of propodeum at most extending up to level of spiracle (a); dorsal area of propodeum triangularly protruding medio-posteriorly and its posterior surface impunctate to remotely punctate (b); vertex behind posterior ocelli impunctate (c); body black, 20-30 mm long (d); wings entirely fuscous to yellowish subhyaline (e).

Campsomeriella Betrem
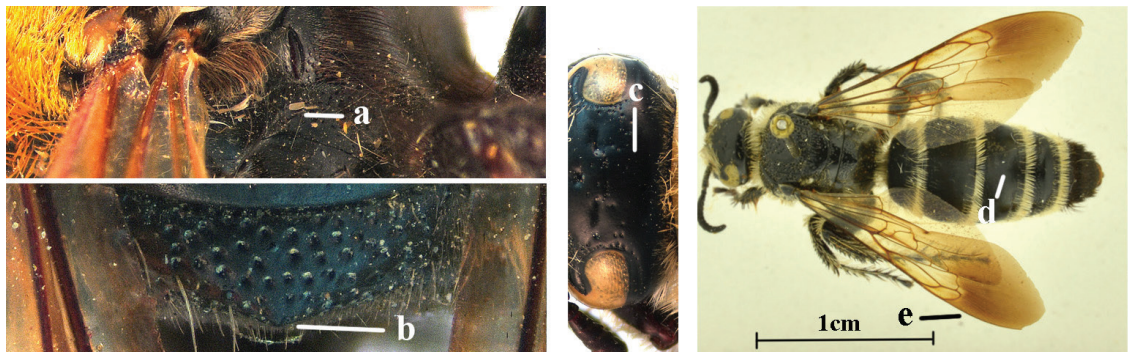

- $\quad$ Lateral carina of propodeum extended beyond level of spiracle (aa); dorsal area of propodeum truncated medio-posteriorly and its posterior surface densely punctate, at least dorsally (bb); vertex behind posterior ocelli with sparse to dense punctation (cc); metasoma partly yellow or red, body length more than $30 \mathrm{~mm}$ (dd); wings dark brown (ee).....
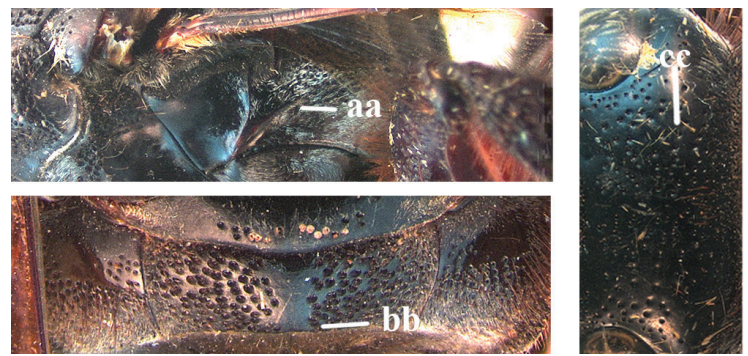

Sericocampsomeris Betrem

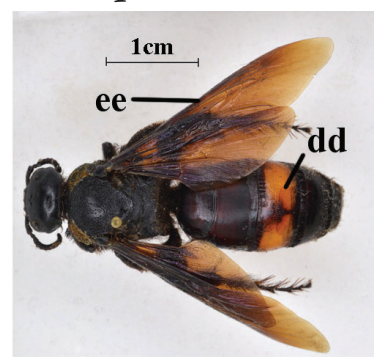


$7 \quad$ Frons with cluster of deep punctures in front of anterior ocellus (a); first submarginal cell of fore wing almost entirely setose (b); fore wing dark brown subapically (c).....

Phalerimeris Betrem
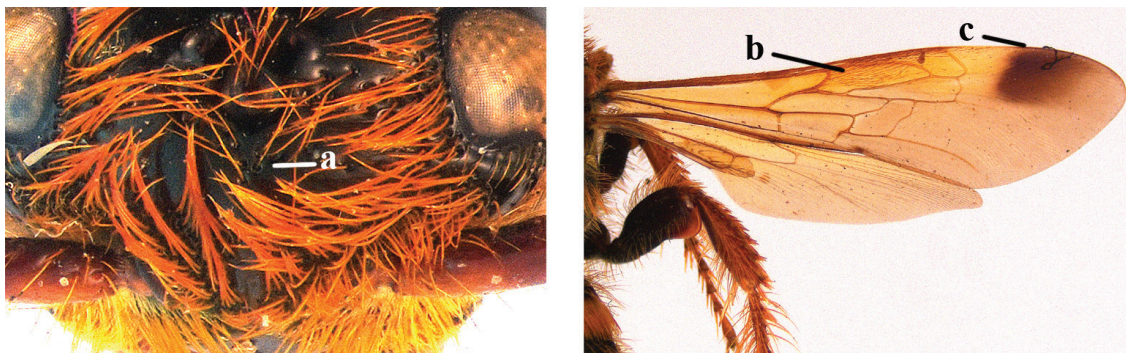

Frons usually without deep punctures in front of anterior ocellus (aa); first submarginal cell fore wing glabrous, except for some setae anteriorly (bb); fore wing at most indistinctly smoky subapically (cc)

Megacampsomeris Betrem
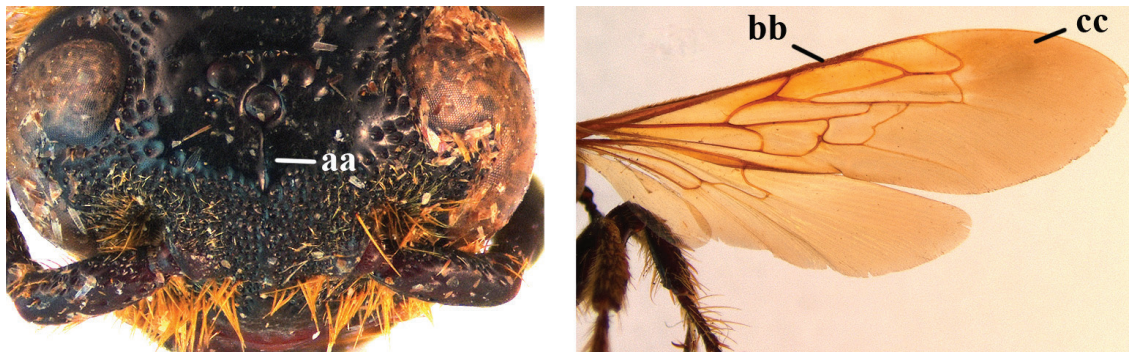

Length of body $5-15 \mathrm{~mm}$; frontal spatium sparsely punctate, intervals between punctures larger than puncture diameters, especially medially (a); scutellum and metanotum usually marked with yellow spots; T1 always with yellow apical band which usually narrowed medially (b); parameres more slender, 4.6x longer than wide (c). [Note: As far as is known, vein $2 \mathrm{~m}$-cu of fore wing is always developed in Chinese species, but this vein is occasionally reduced or absent in some species]

Micromeriella Betrem
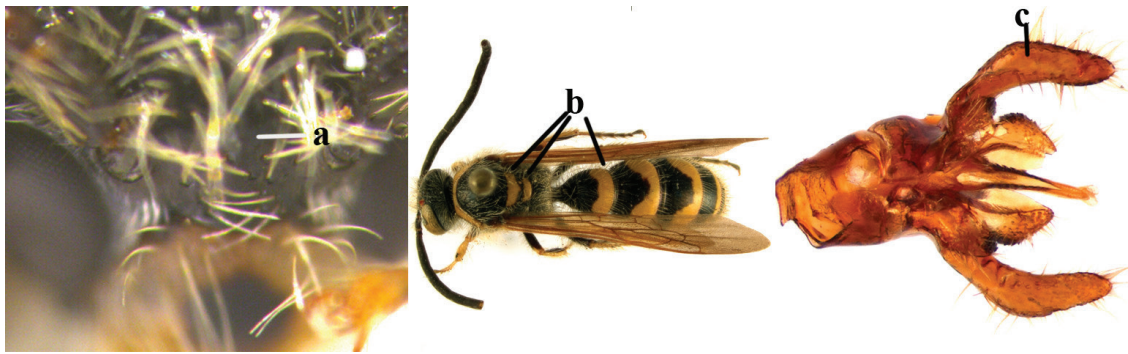
- $\quad$ Length of body $20-30 \mathrm{~mm}$; frontal spatium with dense punctation, intervals mostly smaller than puncture diameter (aa); yellow spots absent or present on scutellum and metanotum and shape of yellow apical band of first tergite variable (bb); parameres robust, $3.2 \times$ longer than wide (cc) . .9
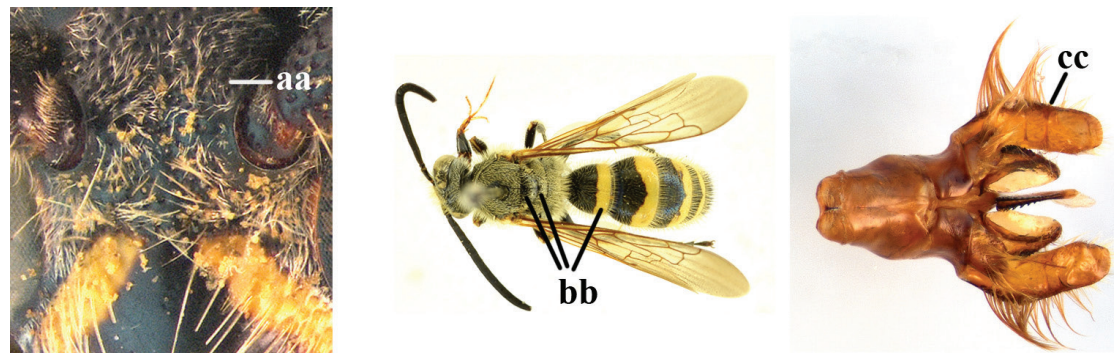

Head distinctly broader than high in frontal view (width approx. $1.3 \times$ height) (a); frons largely impunctate and with a large, flat, triangular area in front of anterior ocellus (b); apical metasomal sternites usually with dense erect setae (copulatory brushes) (c); parameres distinctly angled in middle, not narrowed apicad, basal part of volsellae lacking dense setae (d)

Campsomeriella Beterem
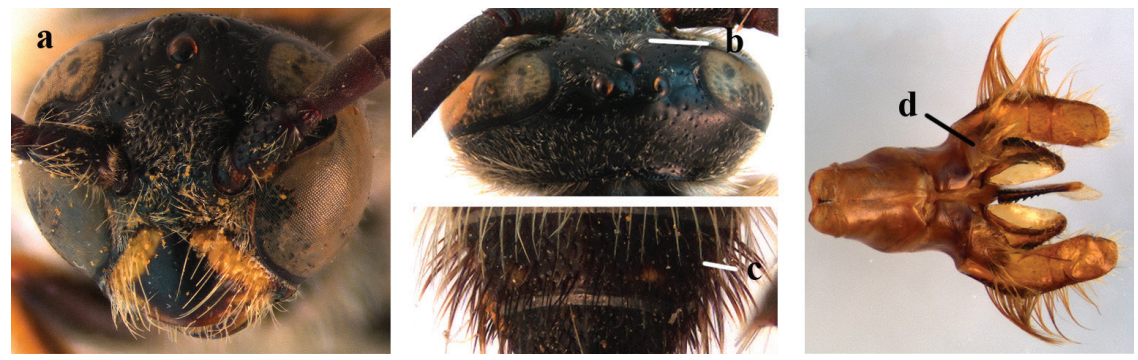

Head almost as broad as high in frontal view (width at most $1.1 \times$ height) (aa); frons without a large impunctate area or triangular area in front of anterior ocellus (bb); apical metasomal sternites without dense erect setae (cc); parameres usually rounded in middle, narrower apicad, basal part of volsellae with sparse to dense setae $(\mathrm{dd})$
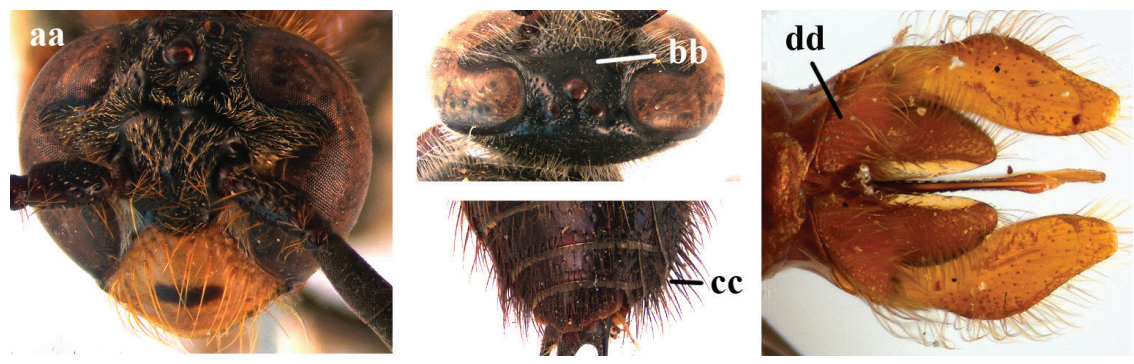
10 Clypeus, mandible, scapula, scutellum and metanotum entirely black, metasoma usually with wide reddish or orange bands on T1-3, often also on apical tergites (a); hind tibial spurs black (b); parameres less slightly converging apically (c)

Sericocampsomeris Betrem
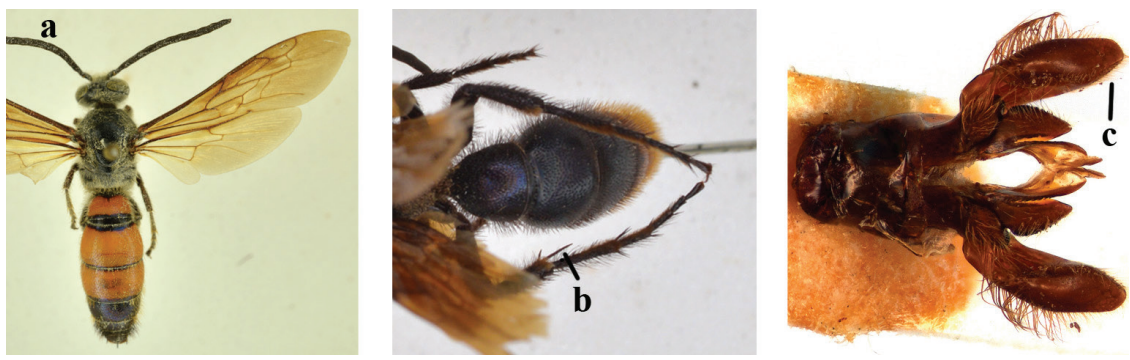

Clypeus, mandible, scapula, scutellum or metanotum often partly yellow, metasoma usually with narrow yellowish to reddish bands at least on basal four tergites (aa); hind tibial spurs white to pale yellowish (bb); parameres strongly converging apically (cc) .11
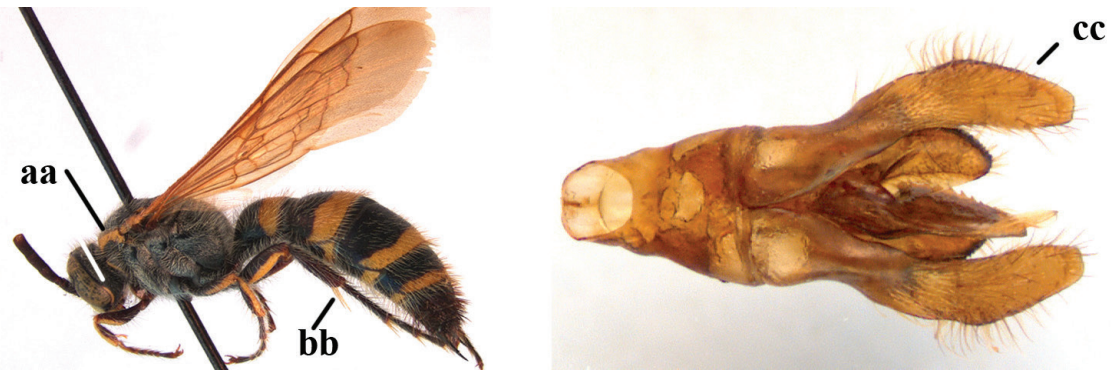

11 Basal part of volsellae with short sparse setae, distance between bases of these setae more than their own diameter (a); length of body less than $14 \mathrm{~mm} . . . .$.

Phalerimeris Betrem

- Basal part of volsellae with long dense setae, distance between the bases of these setae less than their own diameter (aa); length of body more than $15 \mathrm{~mm}$, often $20-30 \mathrm{~mm}$ Megacampsomeris Betrem
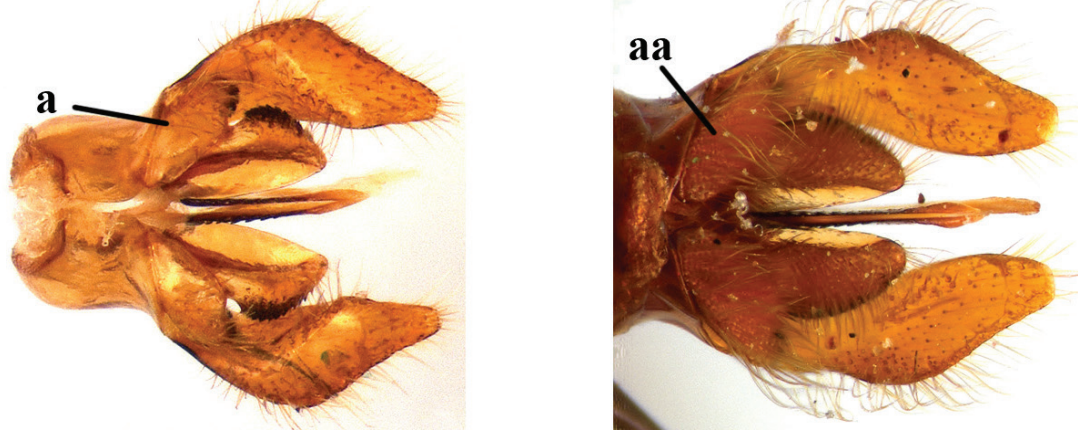
12 Fore wing with two discal cells (a) Liacos Guérin-Méneville

Fore wing with one discal cell (aa)
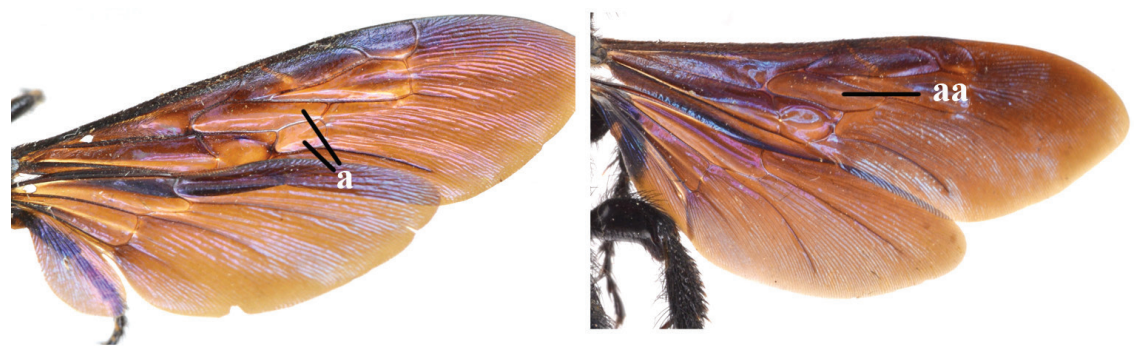

13 Fore wing with three submarginal cells (a) 14

Fore wing with two submarginal cells (aa)
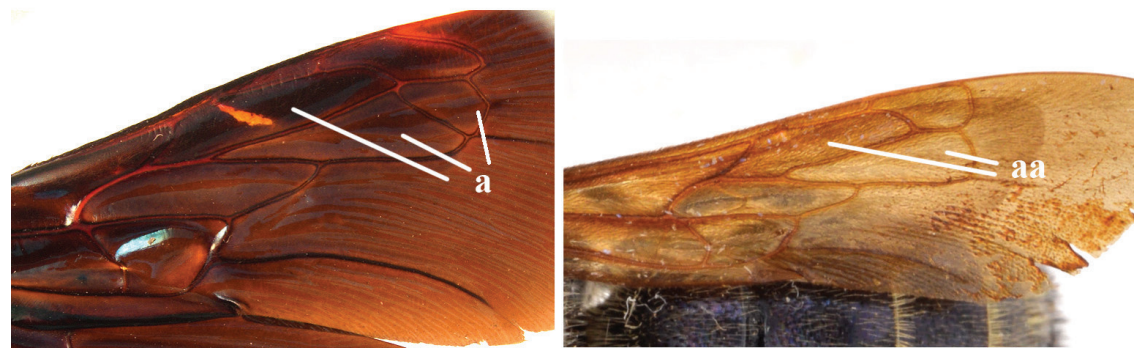

14 Length of body $15-20 \mathrm{~mm}$; frons with an arched ridge, running from one ocular sinus to another and passing behind anterior ocellus, ridge prominent in male (a), but rather weak in female; ocelli on high triangle, posterior tangent to anterior ocellus far away from posterior ocelli in both sexes (b); metasomal setae black (c); T1 without tubercle (d); [only Austroscolia ruficeps (Smith, 1855) occurs in China] Austroscolia Betrem
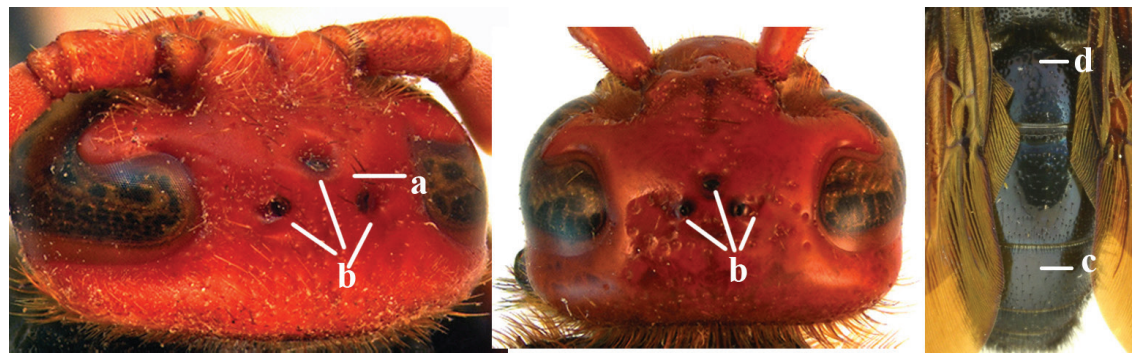
- $\quad$ Length of body 23-42 mm; frons without an arched ridge (aa); ocelli on low triangle, posterior tangent to anterior ocellus nearly touching posterior ocelli in both sexes (bb); setae of T3-6 or T4-6 reddish (cc); T1 with a strong tubercle antero-medially (dd); [only Megascolia (Regiscolia) azurea (Christ, 1791) occurs in China] Megascolia Betrem
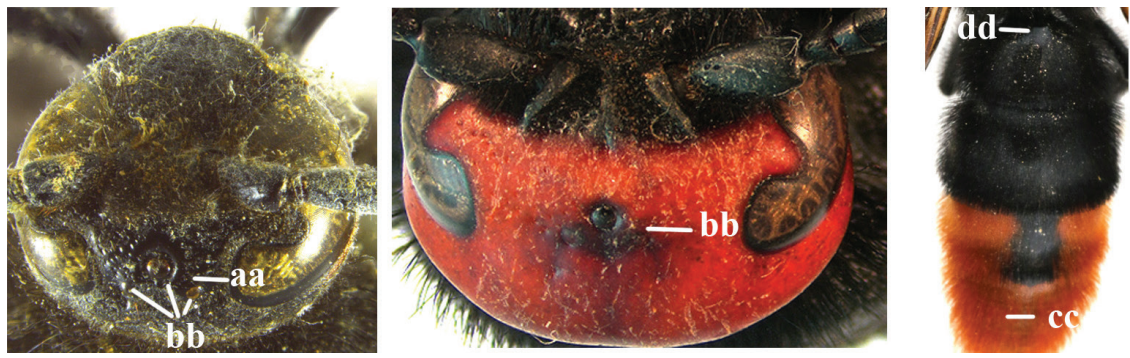

15 Frons often with a transverse ridge (or carina) on the males (a); posteriorly not strongly sloping vertex and temples less receding dorsally (b); metasoma black (c), at most T3 with yellow spots (cc), often with purple and blue reflections

Carinoscolia Betrem

- $\quad$ Frons without transverse carina on the males (aa); vertex strongly sloping posteriorly and temples more receding dorsally (bb); metasoma often with extensive yellow pattern $(\mathrm{ccc})$ and with variable reflections Scolia Fabricius
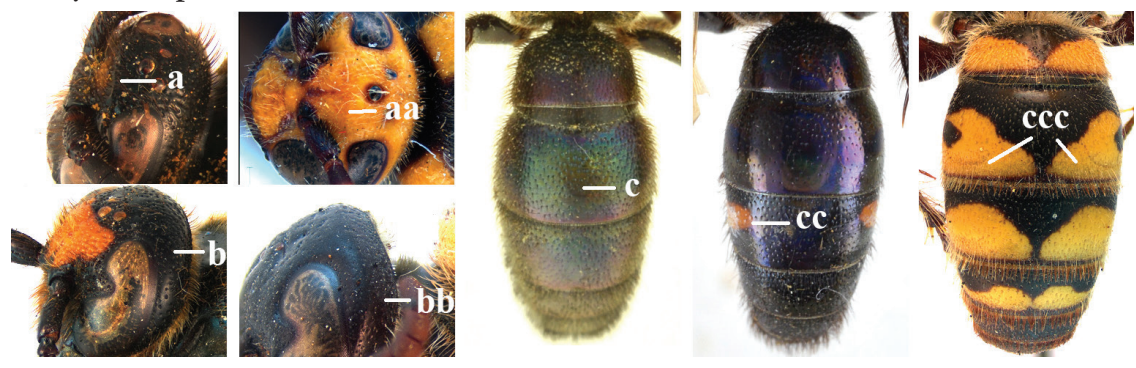

Key to species of genus Campsomeriella from China

$1 \quad$ Females, antenna with 12 segments (female of C. ilanensis (Tsuneki, 1972) unknown) .2

- $\quad$ Males, antenna with 13 segments. 5 
2 Lateral carina of propodeum short, not reaching spiracles (a); spurs of hind tibia black or testaceous (b); setae yellow to reddish on head and mesosoma (c); subgenus Campsomeriella Betrem
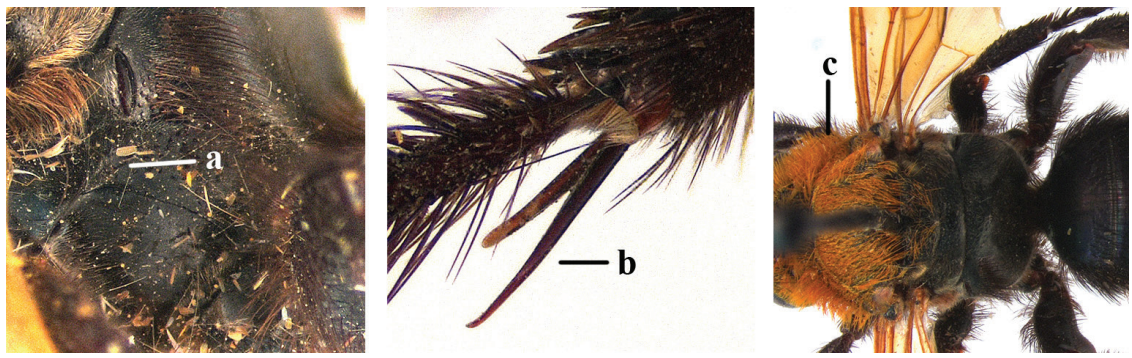

Lateral carina of propodeum long, extending somewhat beyond the spiracles (aa); spurs of hind tibia white (bb); setae white on head and thorax (cc); subgenus Annulimeris Betrem C. (A.) annulata (Fabricius 1793)
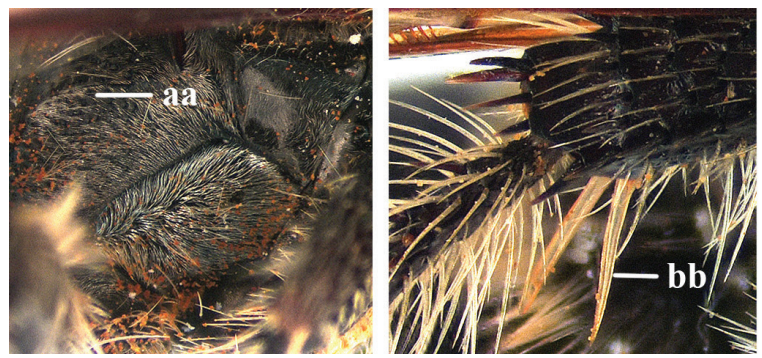

cc

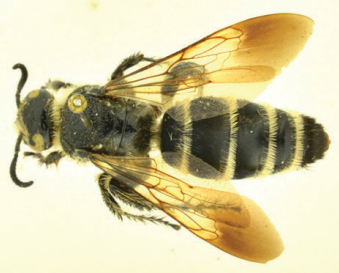

Setae of metasoma entirely black (a); setae on vertex and pronotum red (b); wings distinctly darkened apically (c), sometimes also basally and medially (cc)......

Fringes of T1-T5 white (aa); setae on vertex and pronotum yellow (bb); wings subhyaline, at most, faintly darkened anteriorly (ccc).

C. (C.) sauteri (Betrem, 1928)
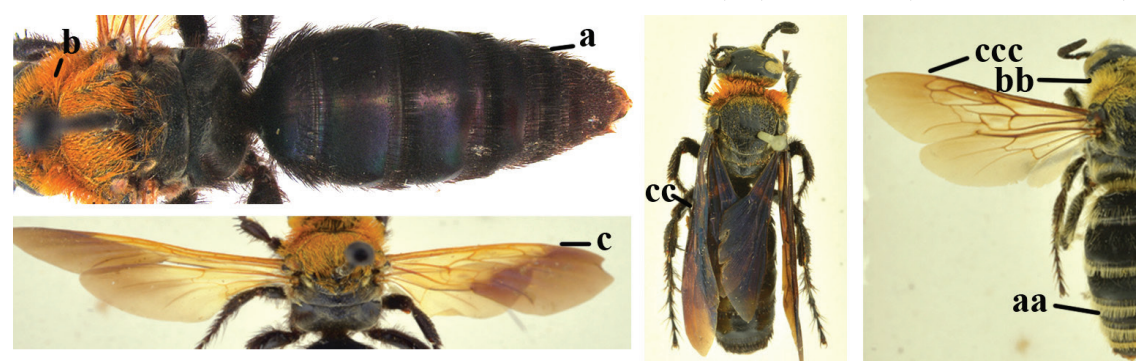
$4 \quad$ Wings with distinctly darkened apical third and remainder subhyaline (a); vertex sparsely and distinctly punctate, densely pubescent (b); disc of clypeus with longitudinal ridge medially (c) ......C. (C.) thoracica (Fabricius, 1787)
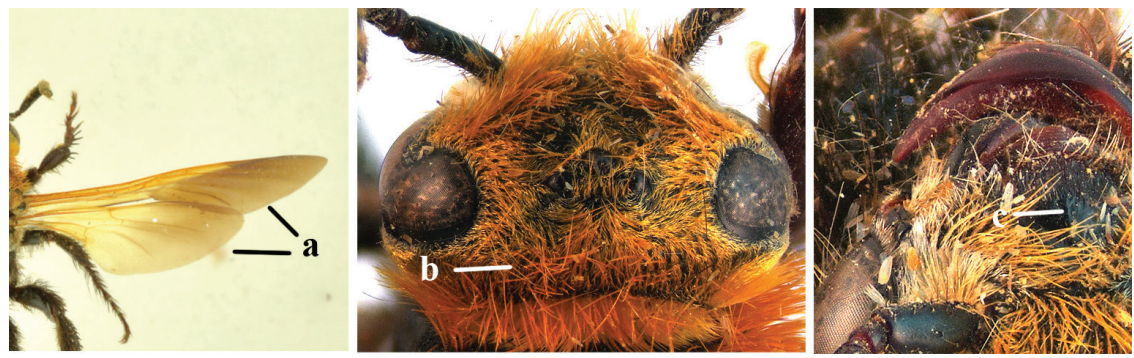

- $\quad$ Wings largely dark brown (aa); vertex smooth, except near occipital carina; disc of clypeus without ridge (cc); [syn. with C.(?) ilanensis (Tsuneki, 1972)] C. (C.) collaris (Fabricius, 1798)
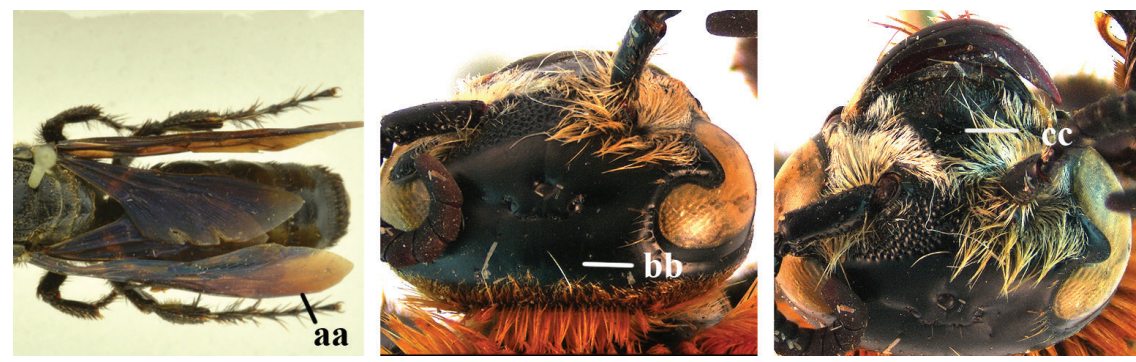

Base of volsella covered with sparse and short setae (a); metanotum black (b) and scutellum sometimes with two yellow spots; subgenus Campsomeriella Betrem
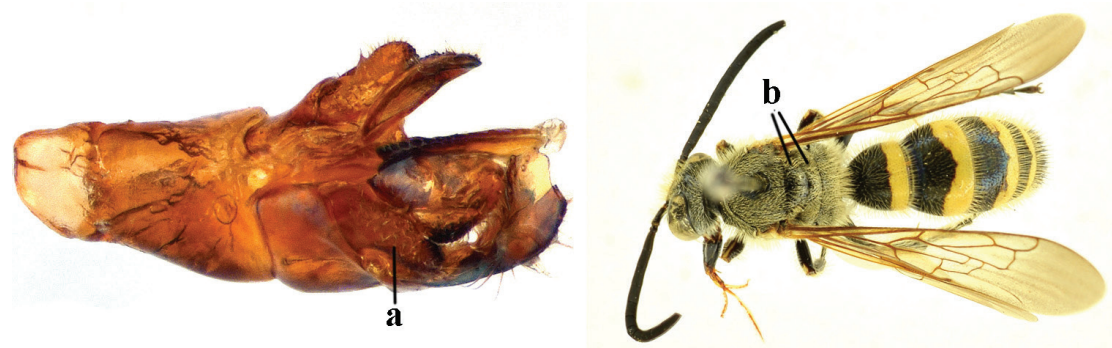

Base of volsella covered with long and dense setae (aa); metanotum and scutellum always with yellow spots (bb); subgenus Annulimeris Betrem ......... C. (A.) annulata (Fabricius 1793)
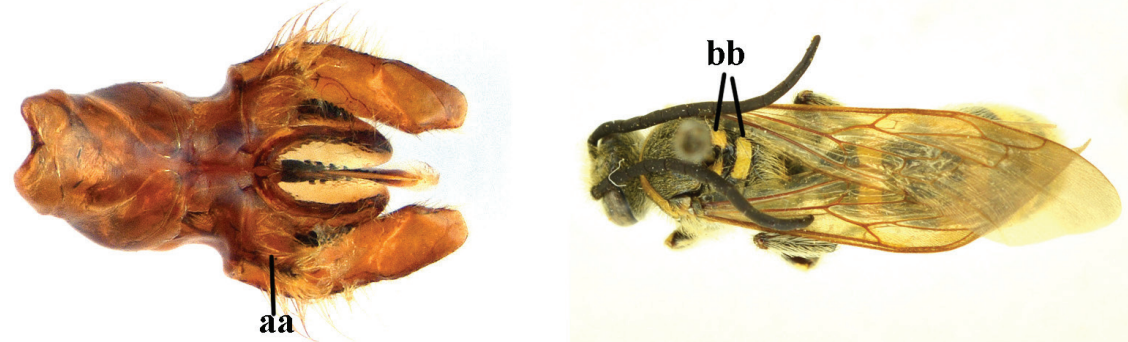
6 Bands of apical metasoma tergites red or orange, wide extending over half of tergites surface; coloured bands often absent on T1 (a); reddish setae covering most of metasoma coloured bands (b)... C. (C.) thoracica (Fabricius, 1787)

- Bands of apical metasoma segments yellow and often narrow, at most covering half of the tergites surface; T1 always with yellow apical band (aa); white setae covering yellow bands; brown to blackish-brown setae on T7 or T5-7 and $\mathrm{T} 1-\mathrm{T} 6$ or $\mathrm{T} 1-\mathrm{T} 4$ with white setae (bb)
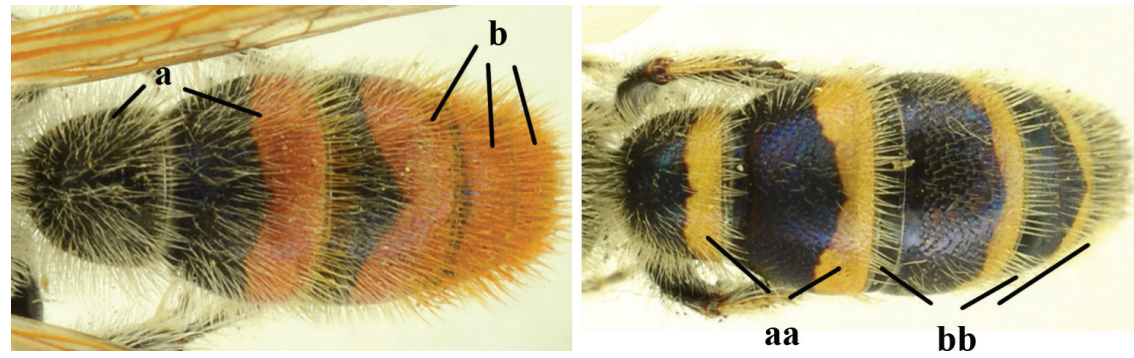

Pronotum yellow posterodorsally (a); middle femur marked with yellow apically; hind tibia extensively yellow (b); yellow band on T3 covering nearly half of its mid-length (c); [syn. with C.(?) ilanensis (Tsuneki, 1972)]

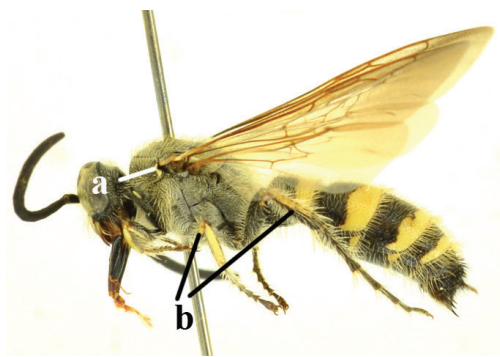

C. $(C$.$) collaris (Fabricius, 1798$

- $\quad$ Pronotum black posterodorsally (aa); middle femur nearly entirely black; hind tibia yellow basally (bb); yellow band on T3 occupying $1 / 4$ of its midlength (cc).....

C. (C.) sauteri (Betrem, 1928)
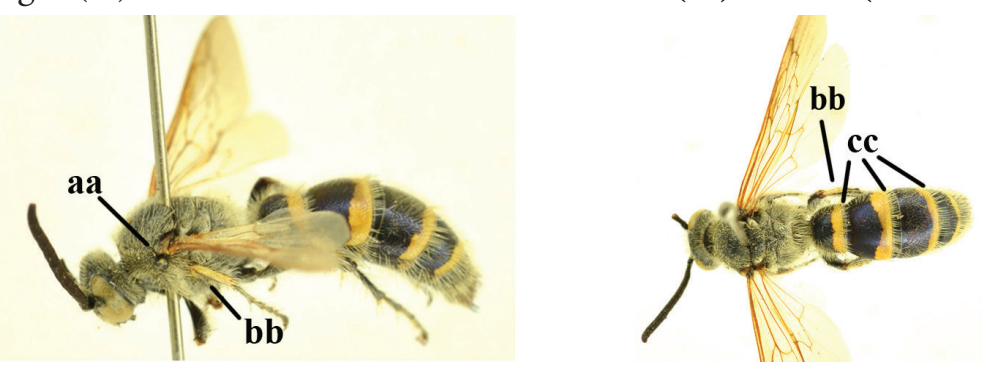

Notes. Only the male holotype of Campsomeriella ilanensis from Taiwan is known. According to the description and drawings by Tsuneki (1972a), C. ilanensis is very similar to $C$. $(C$.) collaris quadrifasciata (Fabricius, 1798) and it could be a synonym of the latter. 


\section{Key to species of Megacampsomeris from China}

1 Female, antenna with 12 segments (female of M. szetschwanensis (Betrem, 1928) unknown)

- $\quad$ Male, antenna with 13 segments (males of M. bella (Bingham, 1897), M. grossa (Fabricius, 1804) and M. stoetzneri (Betrem, 1928) unknown) ................... 14

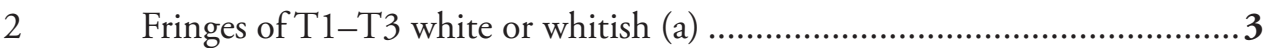

- $\quad$ Fringes of T1-T3 yellow, reddish-yellow or black (aa) .................................8
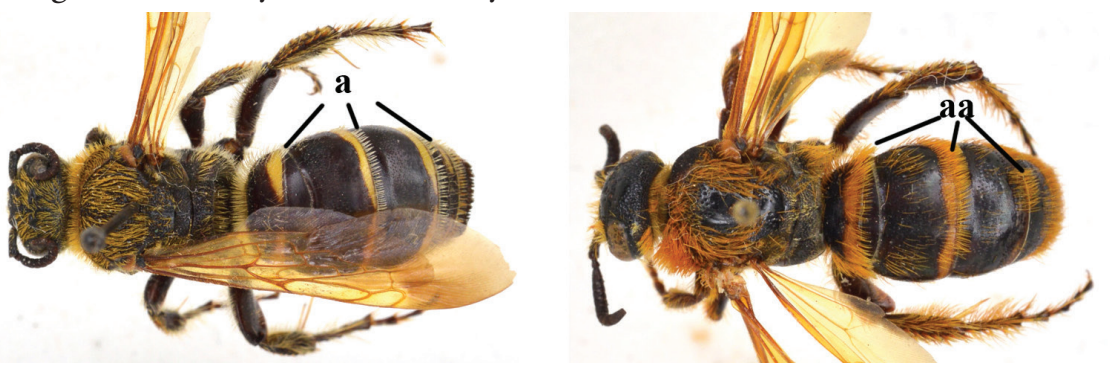

At least T1 more or less yellow or pale yellow posteriorly (a) 4 Metasomal tergites completely black (aa)
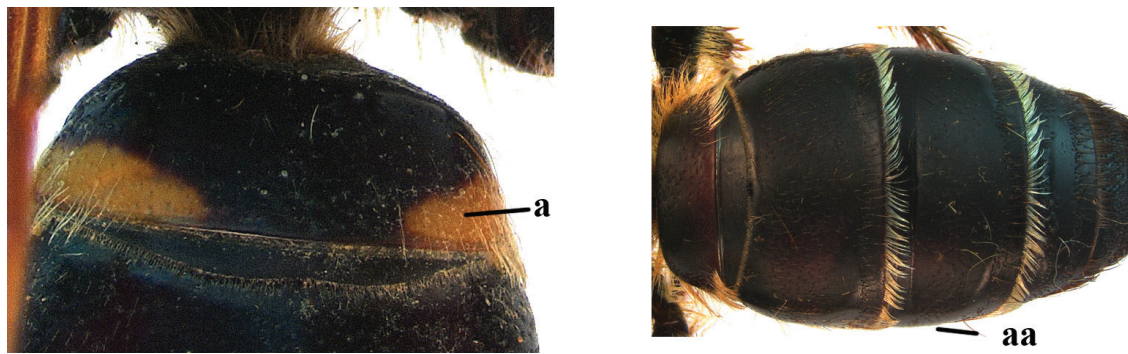

4 Vertex, behind ocelli, largely smooth (a); frons, in front of ocelli, narrowly smooth (b); mesoscutum smooth medially (c) ....M. schulthessi (Betrem, 1928)
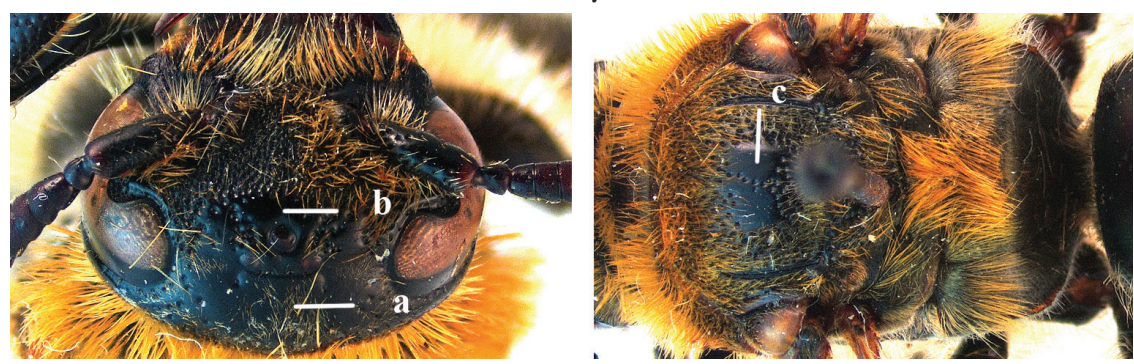
- $\quad$ Vertex (aa) and frons (bb) largely, densely and deeply punctate; mesoscutum

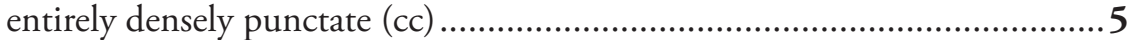
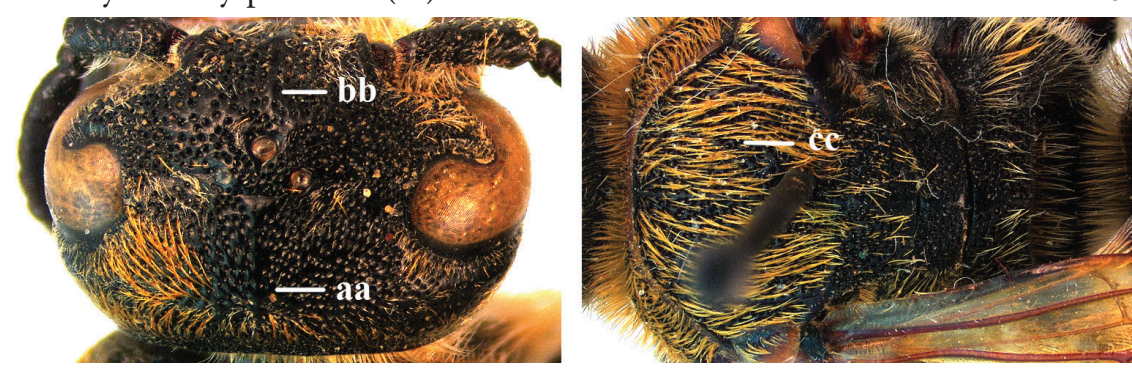

Spiracular corner (a) and vertical portion of upper plate of metapleuron (b) impunctate; upper plate of metapleuron divided by a well-defined ridge into a punctate dorsal portion and an impunctate vertical portion (c) .

M. bella (Bingham, 1897)

- Spiracular corner punctate (aa); vertical portion of upper plate of metapleuron punctate just below transition from dorsal portion and with few punctures along anterior and posterior sutures (bb); transition from dorsal to vertical portion of upper plate of metapleuron gradual, not carina-like (cc)

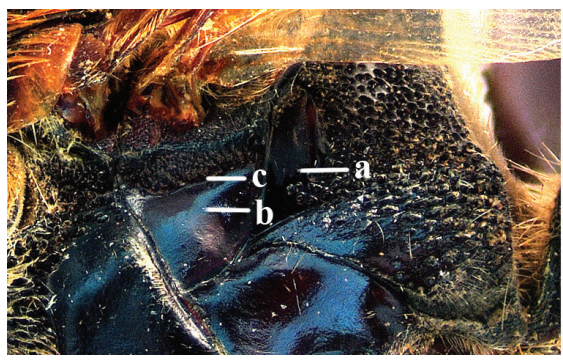

M. stoetzneri (Betrem, 1928)

Vertex entirely smooth behind ocelli (a); setae blackish above antennal insertion and along inner margin of eyes (b) ........M. grossiformis Betrem, 1928 Vertex densely punctate behind ocelli (aa); head setae yellow or yellowishbrown (bb).
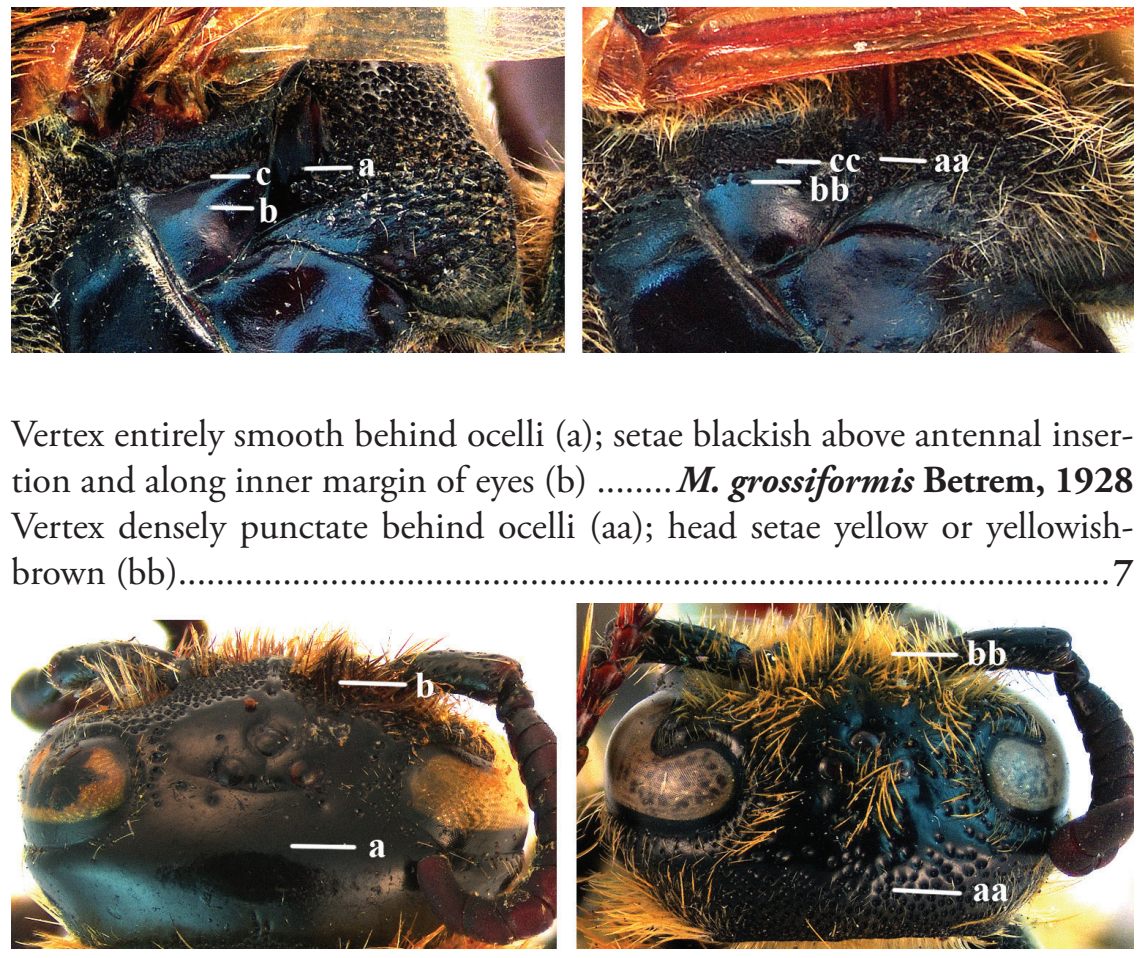
7 Mesoscutum and scutellum smooth, except for few punctures laterally (a); metanotum broadly smooth medially (b) ......M. farrenwhitei Betrem, 1928 Mesoscutum and scutellum nearly entirely densely punctate, except for more or less smooth area posteromedially (aa); metanotum densely punctate $(\mathrm{bb})$ M. grossa (Fabricius, 1804)
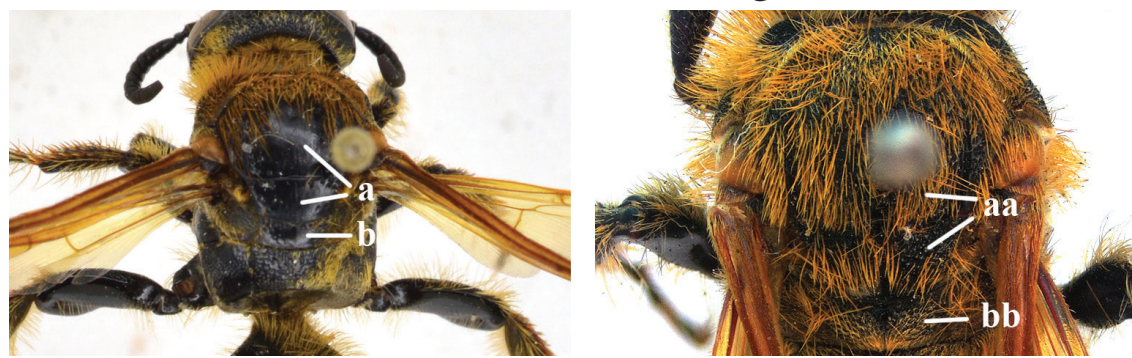

Fringes of T1-T4 blackish-brown to black; wings distinctly darkened

M. binghami (Betrem, 1928)

- $\quad$ Fringes of T1-T4 brown or yellowish-brown (a); wings subhyaline and yellowish (b)

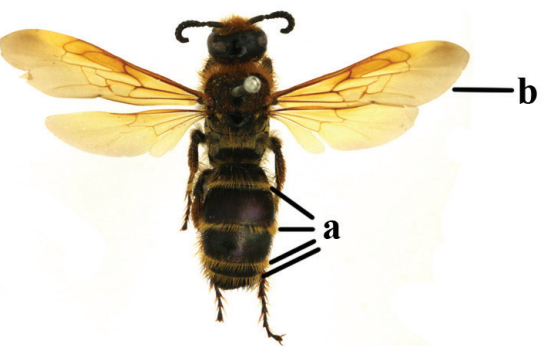

9 T1 and T2, sometimes including T3, with a yellow or pale yellow band posteriorly (a)

- $\quad$ Tergites entirely black (aa) 11
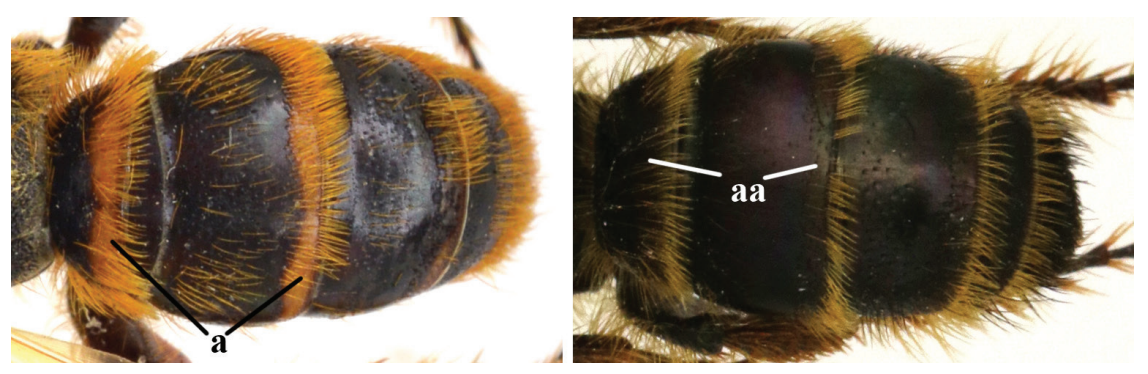

10 Bands on tergites distinct, T3 usually with yellow area posteriorly (a); scutellum largely smooth medially (b); basal elevation of T2 ("gradulus") distinctly developed (c) M. formosensis Betrem, 1928 
- $\quad$ Bands on tergites indistinct, T3 without yellow area (aa); scutellum evenly and densely punctate (bb); basal elevation of T2 absent (cc)

.M. limbata (de Saussure \& Sichel, 1864)
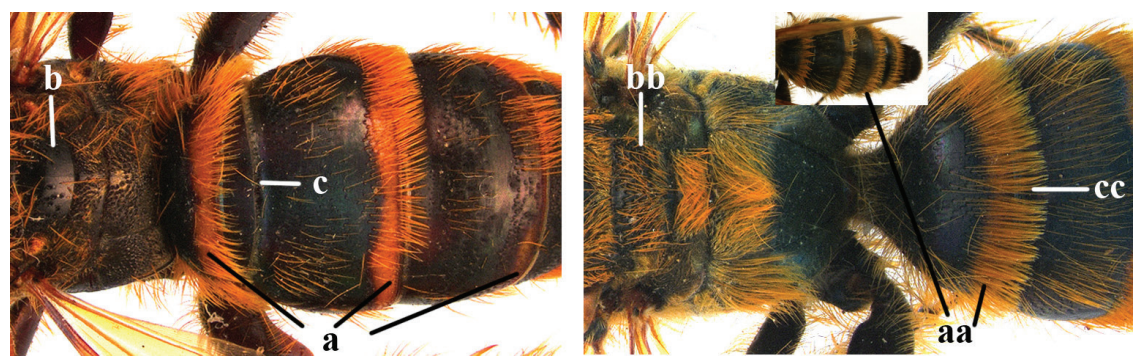

11 Vertex smooth latero-posteriorly (a) M. lindenii (Lepeletier, 1845)

Vertex coarsely punctate latero-posteriorly (aa)
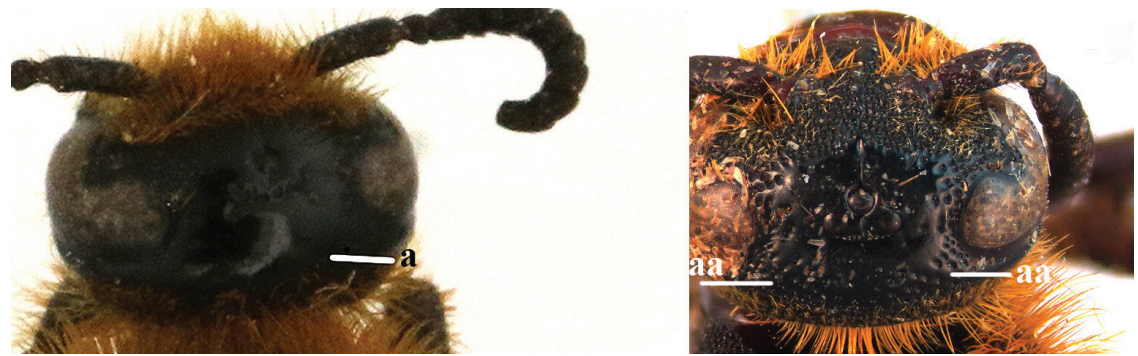

12 Scutellum largely smooth (a); wings without infuscation subapically (b); median groove of frons distinct (c) M. farrenwhitei Betrem, 1928
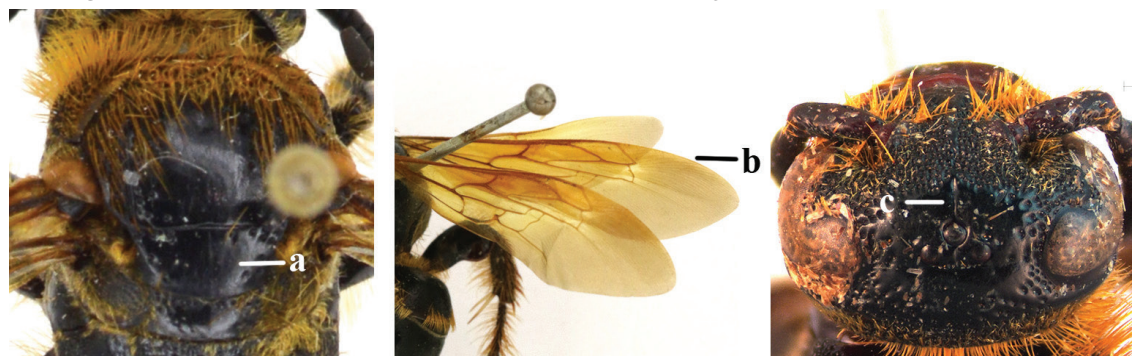

Scutellum punctate anteriorly (aa), if largely smooth, then wings with subapical infuscation (bb); median groove of frons partly or almost completely missing (cc).
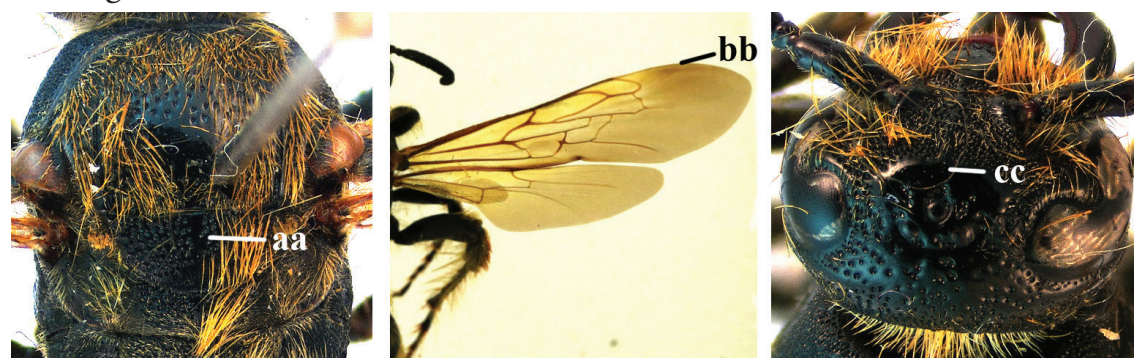
13 Fringes of T1-T4 yellowish-brown and black on other tergites (a); antenna black (b); scutellum entirely or only anteriorly punctate (c)

M. prismatica (Smith, 1855)
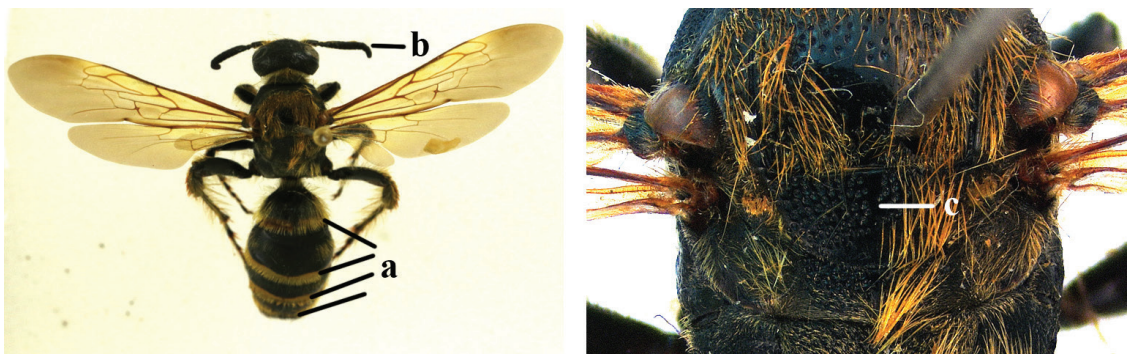

- $\quad$ Tergites setae yellowish-brown; antenna reddish-yellow; scutellum largely smooth M. ceylonica (Kirby, 1889)

14 Tergites setae red or reddish-brown (a); legs yellowish-brown (b)

M. ceylonica (Kirby, 1889)

- $\quad$ Setae pale yellowish (aa) or reddish-brown and, on T6-T7, black (aaa); legs mainly black (bb).
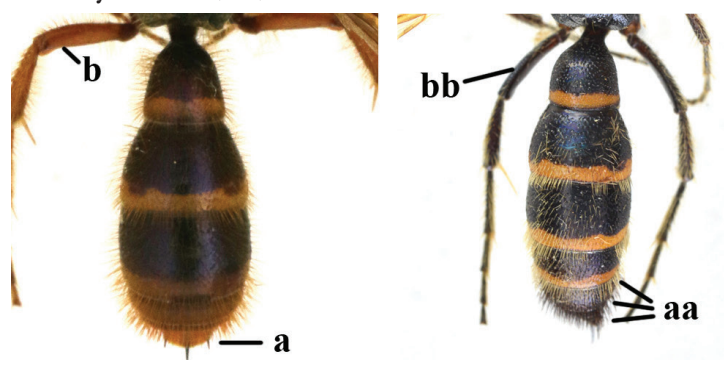
15

15 Clypeus mostly black, at most with two small lateral yellowish areas above mandible base. 16

- $\quad$ Clypeus at least broadly yellow laterally (a) 19

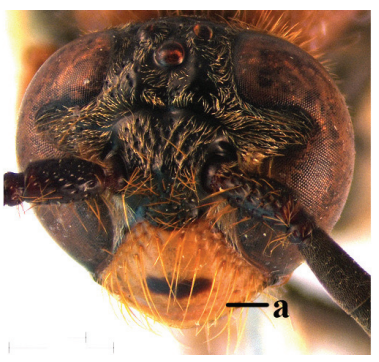


16 Wings more or less darkened (a) M. binghami (Betrem, 1928) Wings subhyaline (aa)
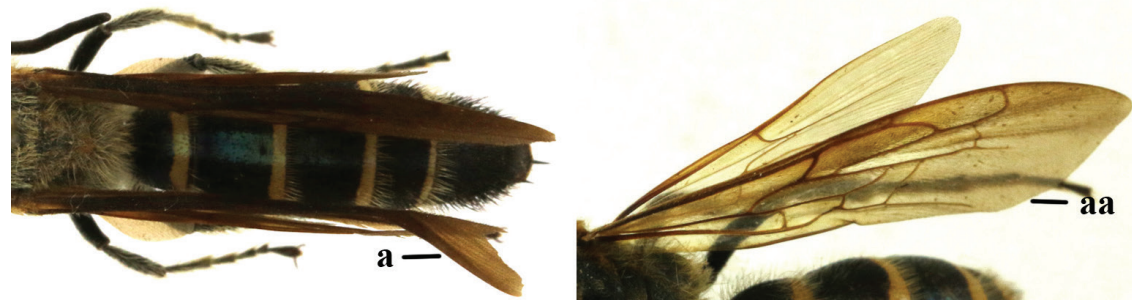

17 Posterodorsal margin of pronotum pale yellow; scutellum without mediolongitudinal carina M. schulthessi (Betrem, 1928)

- $\quad$ Posterodorsal margin of pronotum only indistinctly narrowly yellow posteriorly (a); scutellum and metanotum with a more or less distinct medio-longitudinal carina $(b)$ 18
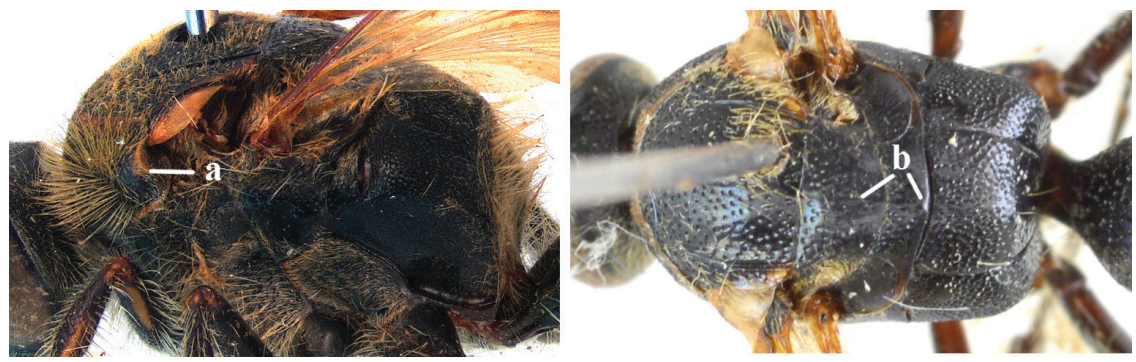

Setae on mesosoma yellowish and sparse (a); punctures sparse, intervals $1-2 \times$ larger than puncture diameter (b) M. formosensis (Betrem, 1928) Setae on mesosoma reddish and dense (aa); punctures dense, intervals often smaller than puncture diameter (bb) .... M. szetschwanensis (Betrem, 1928)
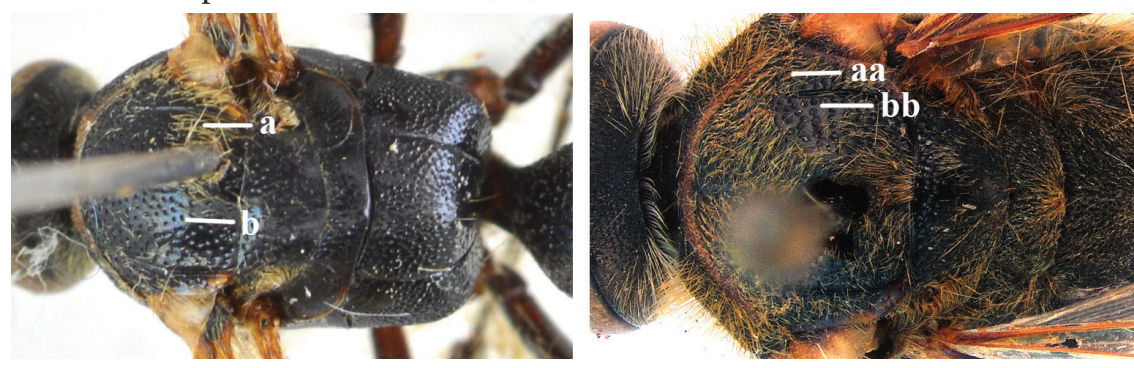
19 Clypeus always black medio-ventrally and remainder more or less yellow (a)

- $\quad$ Clypeus always yellow medially (aa)
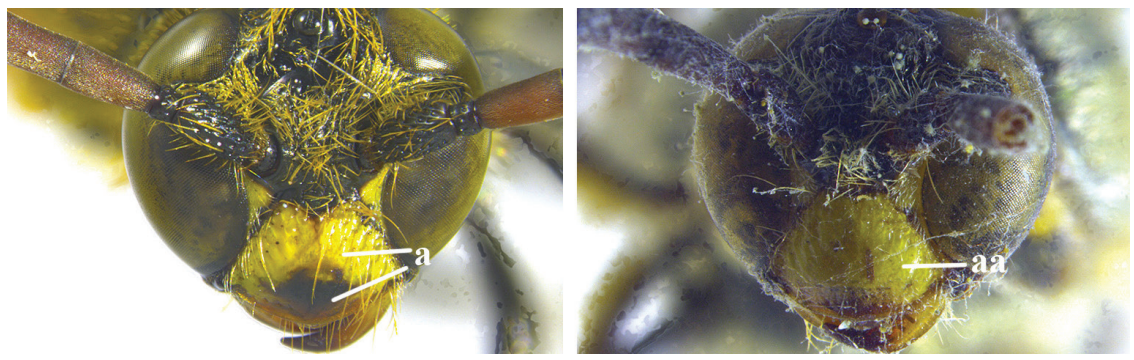

Yellow bands on T1 wide, covering nearly $1 / 3$ of $\mathrm{T} 1$; scutellum always with two lateral yellow spots

M. limbata (de Saussure \& Sichel, 1864)

Yellow bands on T1 narrow, at most covering 1/5 of T1; scutellum often entirely black, rarely with yellow spots

21 Hind femur yellow ventrally (a); S2-S4 often with yellow cuneate maculae lateroapically (b) M. farrenwhitei Betrem, 1928 Hind femur black ventrally (aa); S2-S4 rarely with yellow maculae (bb) M. prismatica (Smith, 1855)
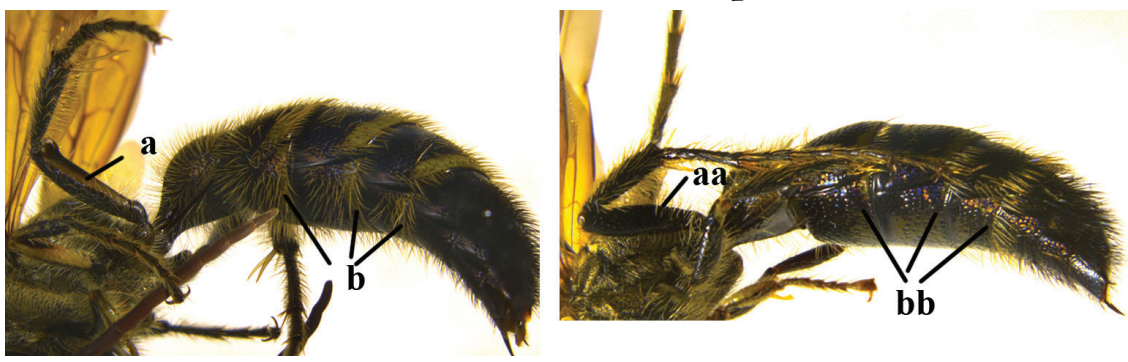

22 T5 usually with yellow band posteriorly; setae of mesosoma dirty white; pronotum black M. grossiformis Betrem, 1928 T5 without a yellow band (a); setae of mesosoma reddish or yellowish-brown (b); pronotum entirely or mostly reddish-yellow (c)

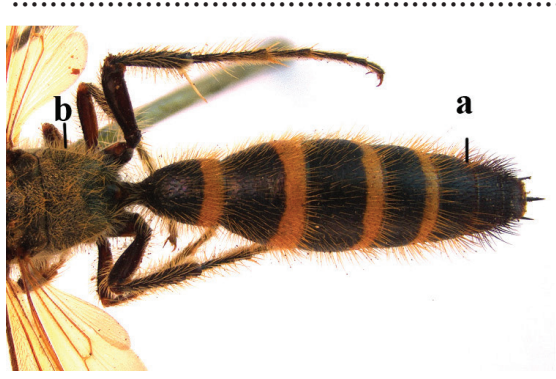

M. lindenii (Lepeletier, 1845)

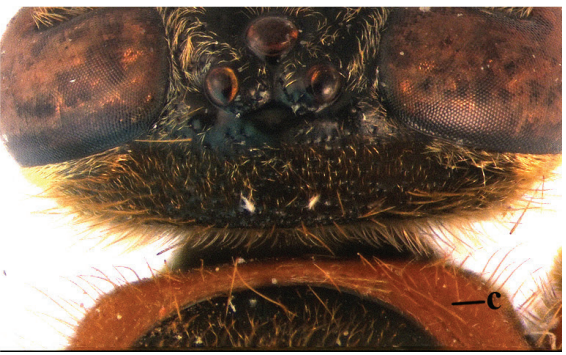


Notes. Males of this genus are difficult to recognise, the key above is a practical key to the males present in the material we have studied and is just a first attempt. The male of $M$. farrenwhitei Betrem, 1928 is here recorded for the first time worldwide. However, males identified as M. szetschwanensis (Betrem, 1928) could be the male of M. stoetzneri Betrem or another species, since the female of $M$. szetschwanensis and the males of M. bella (Bingham, 1897), M. grossa (Fabricius, 1804) and M. stoetzneri (Betrem, 1928) are unknown and the forma A (in Betrem 1941, typical forma of C. szetschwanensis) specimen of $M$. szetschwanensis carries an identical collection label as the holotype female of M. stoetzneri (Schulten 2011).

\section{Key to species of Sericocampsomeris}

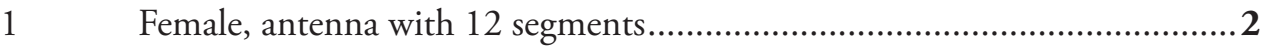

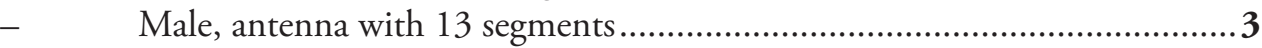

2 Pronotum posterodorsally and upper margin of clypeus with golden setae (a); metasoma setae dark brown, except indistinctly reddish-brown setae on epipygium (b); metanotum and propodeum densely punctate (c)

S. degaullei (Betrem, 1928)

- $\quad$ Pronotum posterodorsally and clypeus with black setae (aa); setae on T2 or T5-T7 reddish-golden (bb); metanotum and median part of propodeum largely smooth (cc)....

S. rubromaculata (Smith, 1855)
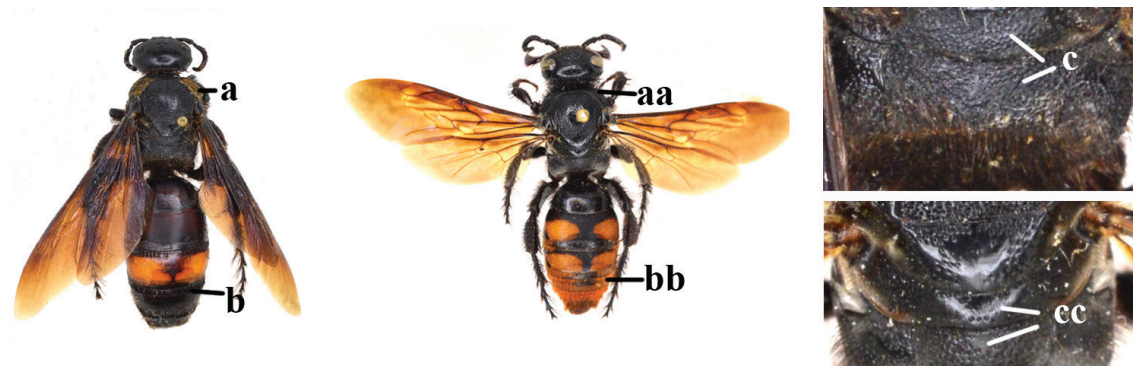

3 Posterior part of T3 and T4-T7 bright reddish-yellow (a); wings infuscate (b); scutellum and metanotum with a continuous medio-longitudinal carina (c)

S. degaullei (Betrem, 1928)

- $\quad$ T1-T3 predominantly reddish-yellow with pale yellow setae, except for black setae on T5/T6-T7 (aa); wings hyaline (bb); scutellum and metanotum without medio-longitudinal carina (cc) S. rubromaculata (Smith, 1855)
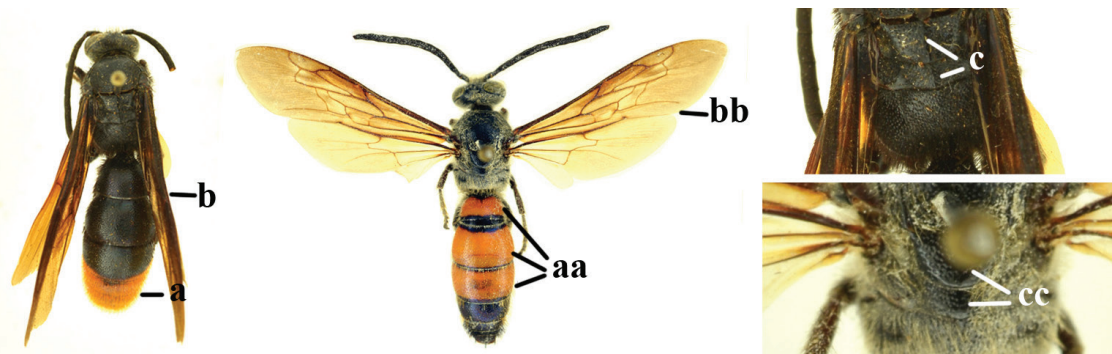


\section{Key to species of Carinoscolia Betrem from China}

1 Frons with a distinct transverse carina present in front of anterior ocellus in both sexes (a); head dark in female (b)

C. nipponensis Uchida, 1933

- $\quad$ Frons without transverse carina, at most with distinct transverse ridge present in males (aa), but often with more or less denser punctate depression before a relatively higher area in both sexes (aaa); head with more or less yellow areas (bb)
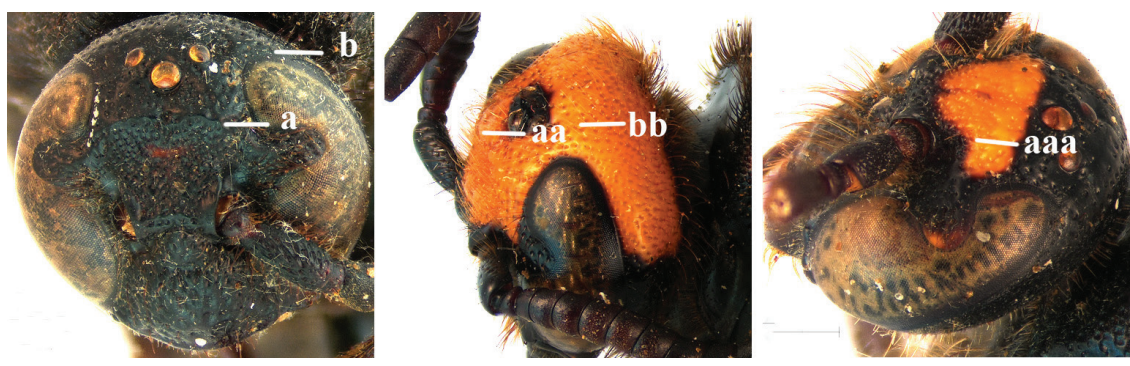

Frons with a distinct transverse ridge in male (a); pronotum in both sexes yellow laterally (b); T3 and sometimes also T4 in female yellow laterally (c), male metasoma wholly black C. yunnanensis (Betrem, 1941)
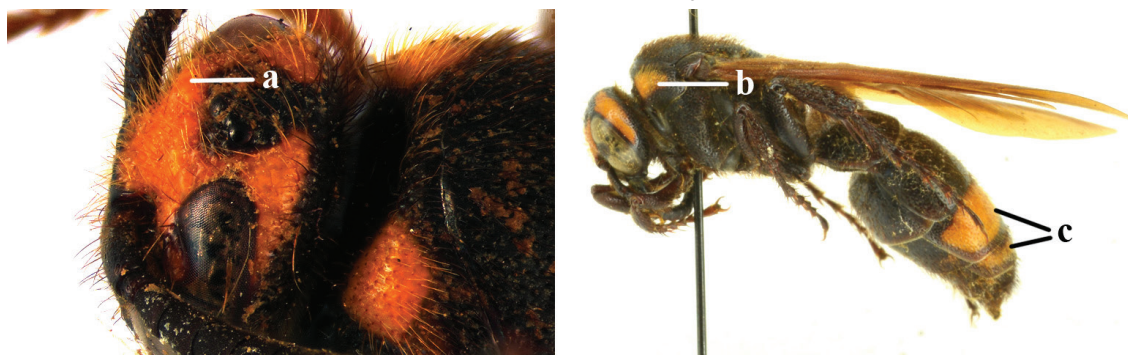

- $\quad$ Frons without distinct transverse ridge in male, often replaced by a more or less denser punctate depression (aa); pronotum in both sexes black laterally (rarely with small round yellow spot anteriorly in female); T3 of both sexes often with pale yellow lateral spot (cc)

.C. vittifrons (Sichel, 1864)
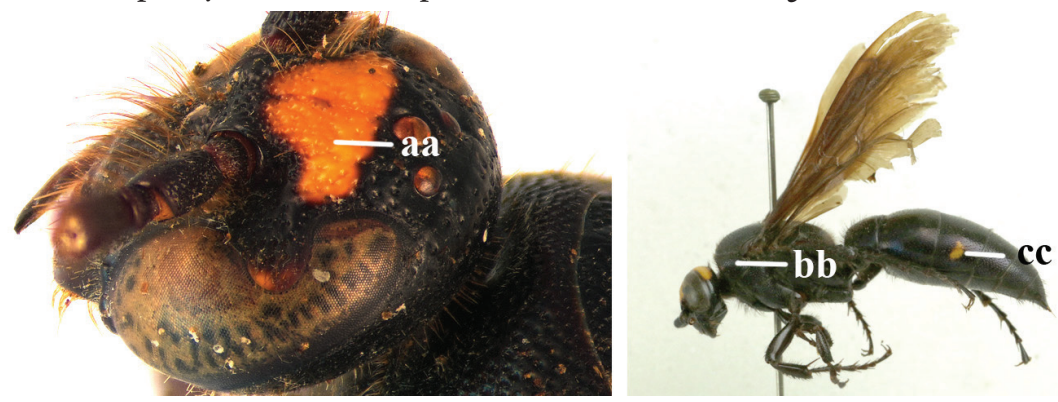


\section{Key to species of the genus Scolia Fabricius from China}

1 Base of volsella covered with a dense brush of silky setae (a); Chinese female either with metasoma entirely black and wings evenly infuscate, lacking purple or blue reflections (b) or with metasoma predominantly yellow and wings bright yellow basally (bb); mainly distributed in Palaearctic Regions of China; subgenus Scolia s. str. Fabricius

- $\quad$ Base of volsella without dense brush of silky setae (aa); females either with metasoma predominantly black and wings dark brown with distinct purple or blue reflections (bbbb) or with red or yellow pattern and wings never bright yellow basally (bbb); mainly distributed in Oriental Regions of China; subgenus Discolia Saussure.
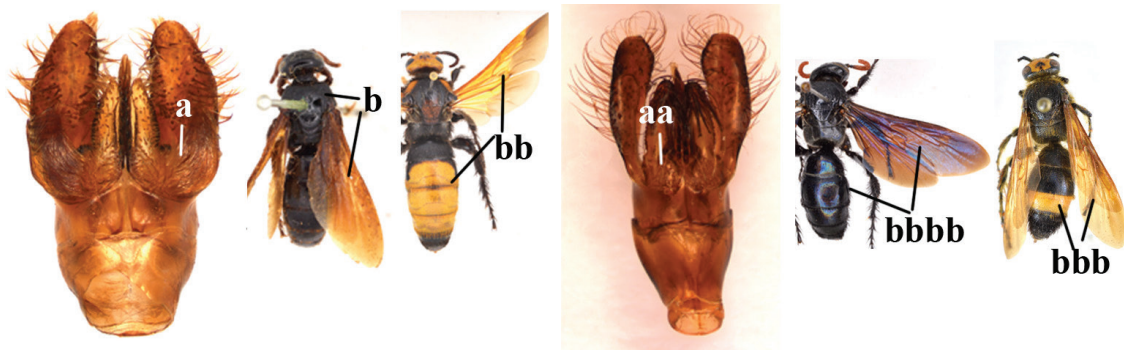

Body black (a); wings not distinctly darkened apically and evenly infuscate (b); clypeus nearly smooth medially (c) S. (S.) concolor Eversmann, 1849
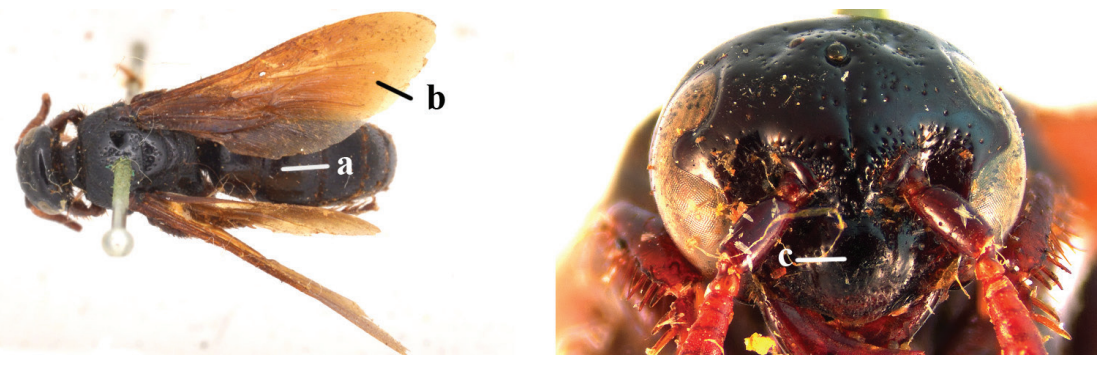

- $\quad$ Metasoma at least partly yellowish (aa); wings with distinct dark apical band and yellowish basally (bb); clypeus strongly rugose or densely punctate medially (cc)......
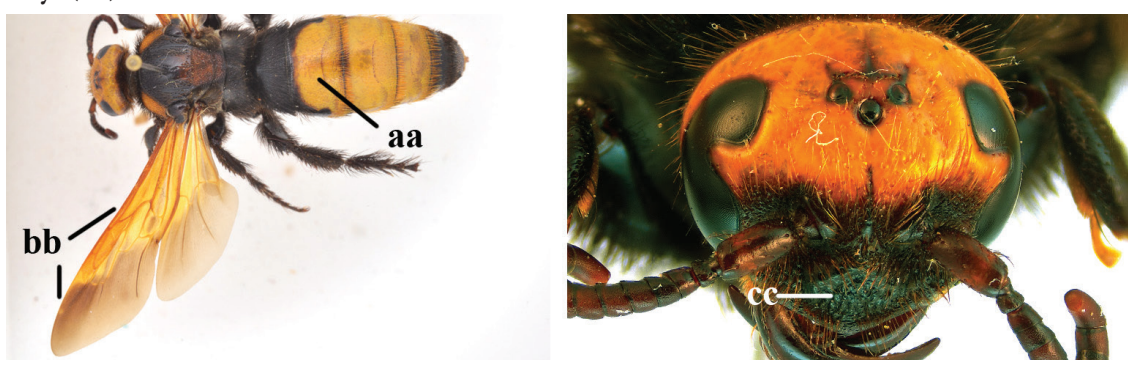
3 Vertex smooth behind ocelli (a); anterior ocellus situated in a narrow and shallow depression (b); vertex and frons yellow (c)

S. (S.) flaviceps Eversmann, 1846

- Vertex densely punctate (aa); anterior ocellus in a broad and deep depression (bb); vertex and frons black (cc)
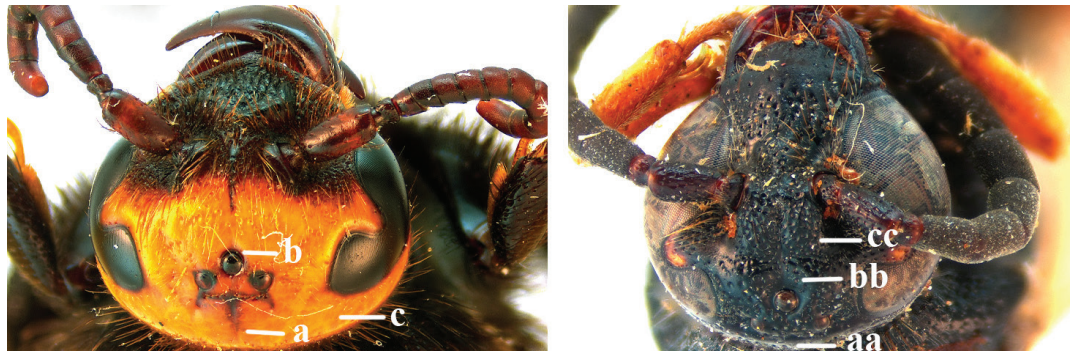

Setae red or yellowish-brown on T2-T7 (sometimes black on epipygium) and black on mesosoma (a)

- $\quad$ Setae on T4-T7 usually black (aa), if setae pale, then mesosoma setae also pale.
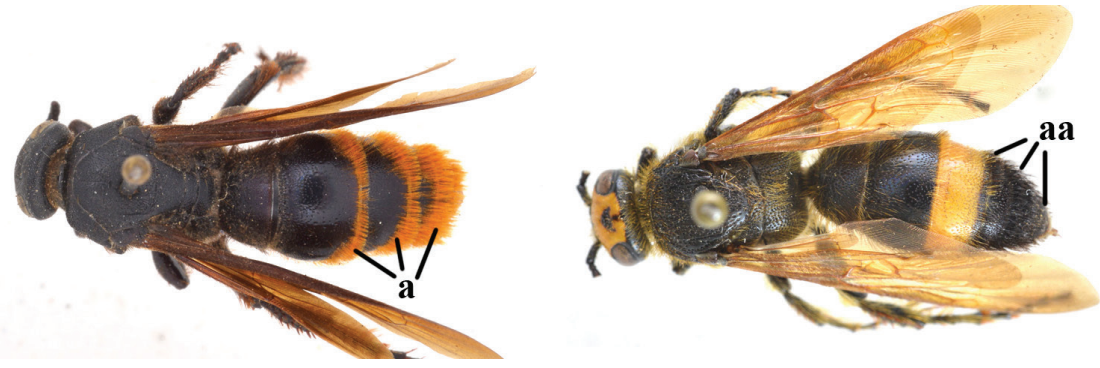

5 Body entirely black, setae red on T2-T7 (a); fore wing without dark subapical spot (b); mesopleuron densely punctate, except partly anteriorly and posteriorly (c) S. (D.) sinensis de Saussure \& Sichel, 1864
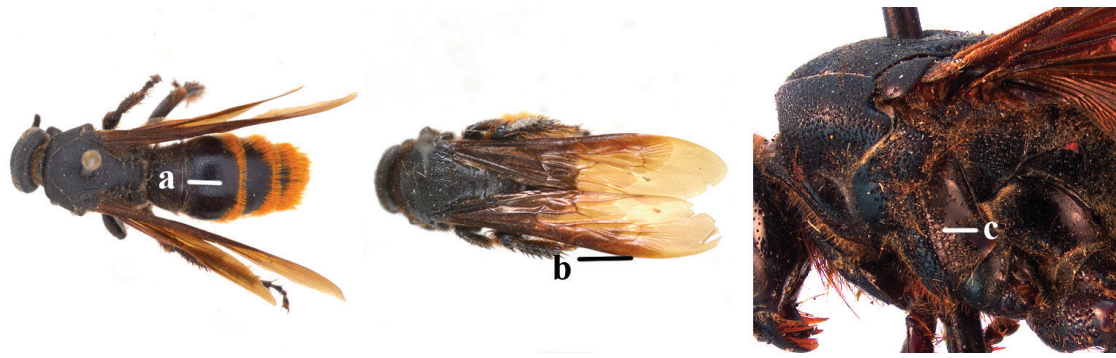

- $\quad$ T3-T6 largely reddish-yellow with red setae, fringes of T2 black; fore wing with a darker subapical spot; mesopleuron nearly smooth, with a few large punctures S. (D.) minowai Uchida, 1933 
Female, antenna with 12 segments (females of S. (D.) bnun Tsuneki, 1972 and $S$. (D.) wusheensis Tsuneki, 1972 unknown) .................................7 Male, antenna with 13 segments (males of S. (D.) inouyei Okamoto, 1924 and $S$. (D.) tigrimaculosa Yamane, 1995 unknown)....

7 Dorso-median area of propodeum smooth to superficially and sparsely punctate (intervals at least as large as puncture diameter) (a)

- Dorso-median area of propodeum more or less strongly and densely punctate (intervals smaller than puncture diameter) (aa)
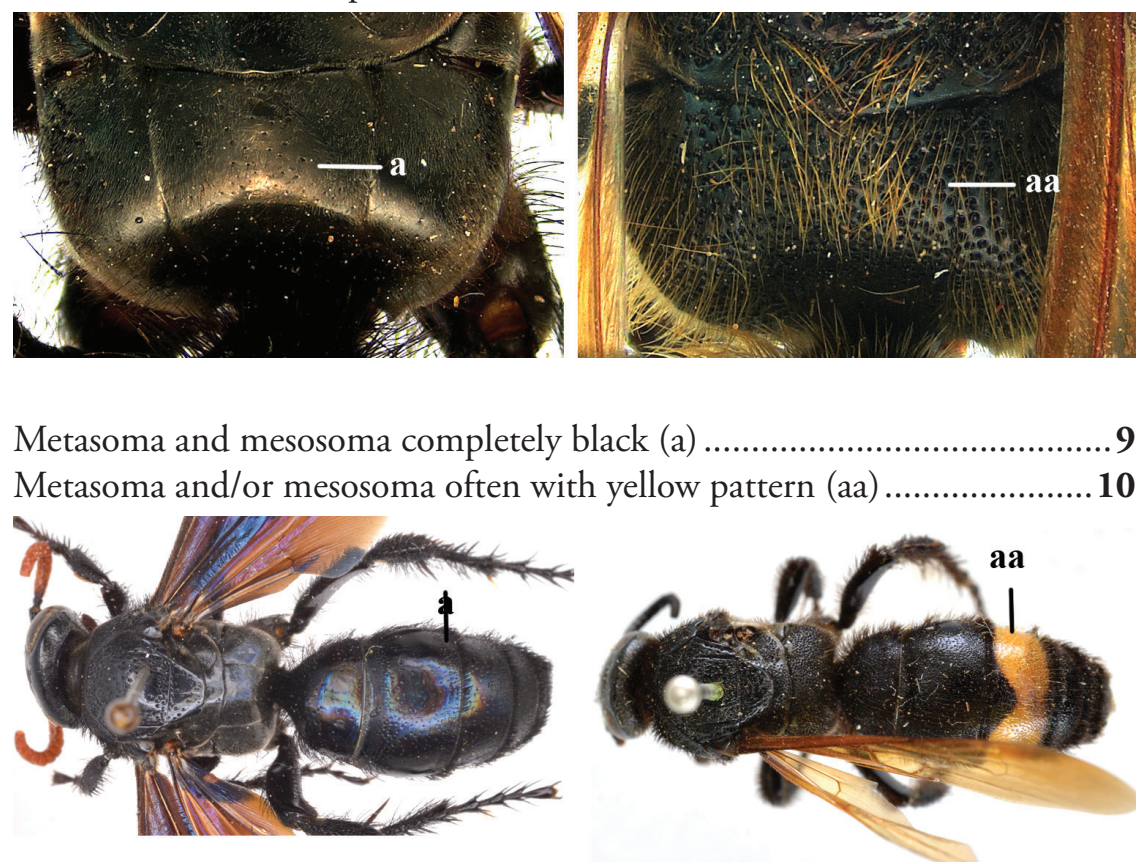

9 Vertex partially to almost entirely yellowish-red (a); metanotum with few, irregular punctures (b); POL:OD:OOL=183:54:251 (c); wings without reflection $(\mathrm{d})$..................................... S. (D.) superciliaris de Saussure, 1864
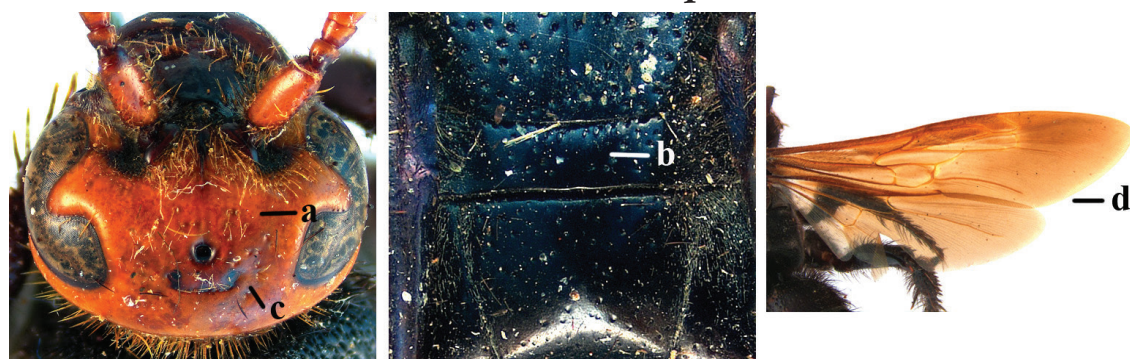
- $\quad$ Vertex entirely black (aa); metanotum and propodeal dorsally almost entirely smooth (bb); POL:OD:OOL=153:69:183 (cc); wings with distinct purple reflection (dd)

S. (D.) affinis Guérin-Méneville, 1845
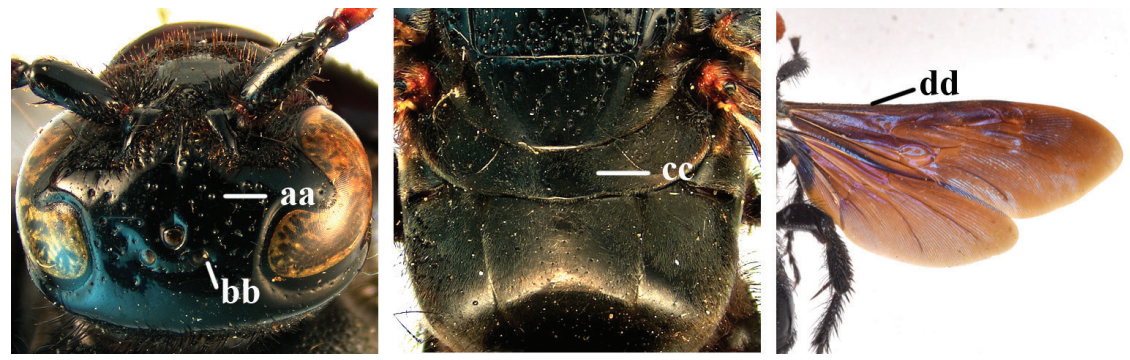

10 T4 black (a); lateral carina just reaching level of propodeal spiracle (b); median groove of frons distinct (c) ................ S. (D.) nobilis de Saussure, 1858
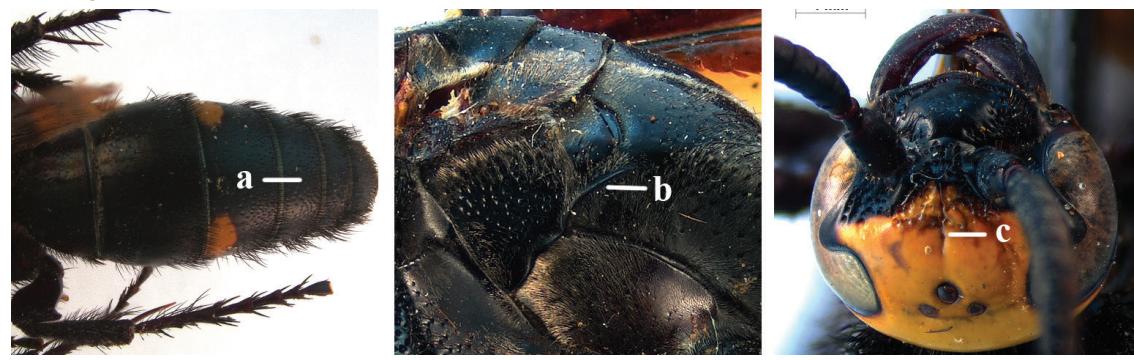

- $\quad$ T4 with a narrow apical yellow band or two lateral yellow spots (aa); lateral carina surpassing level of propodeal spiracle $(\mathrm{bb})$; median groove of frons absent (cc) S. (D.) inouyei Okamoto, 1924
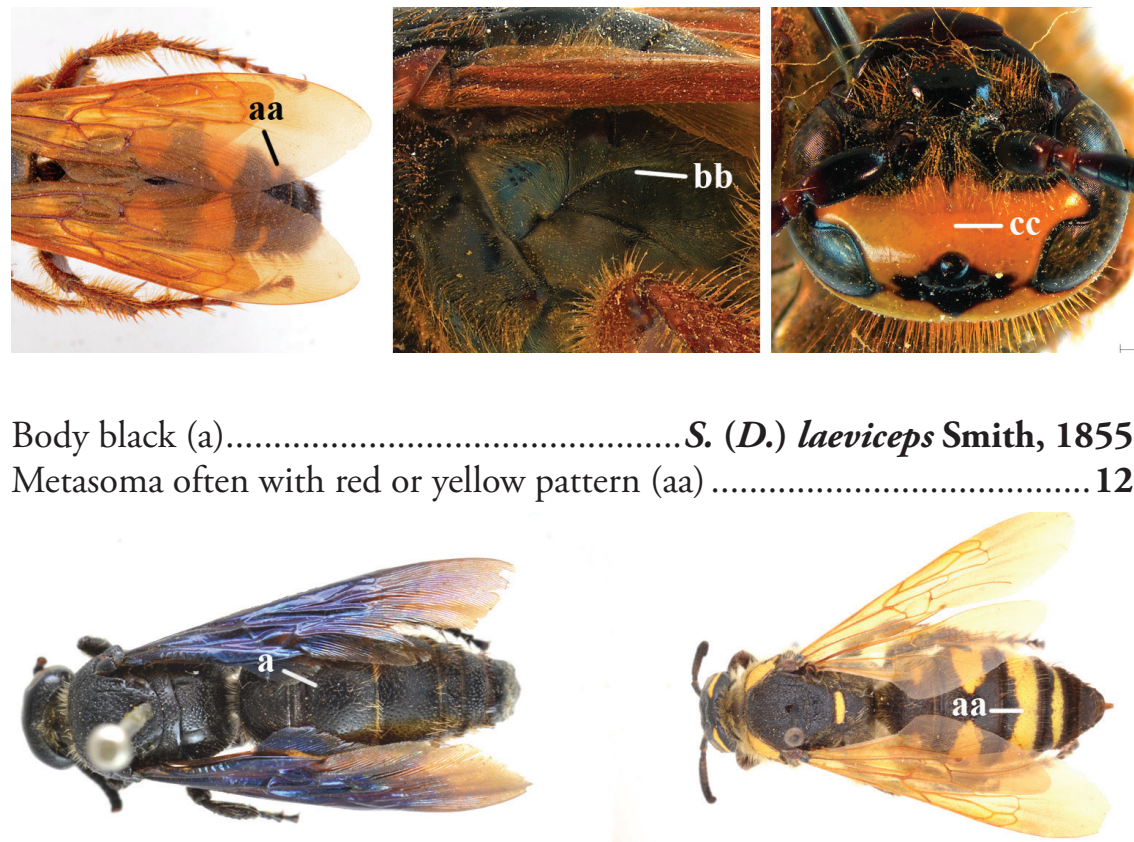
12 Pronotum posterodorsally yellow or red (a)
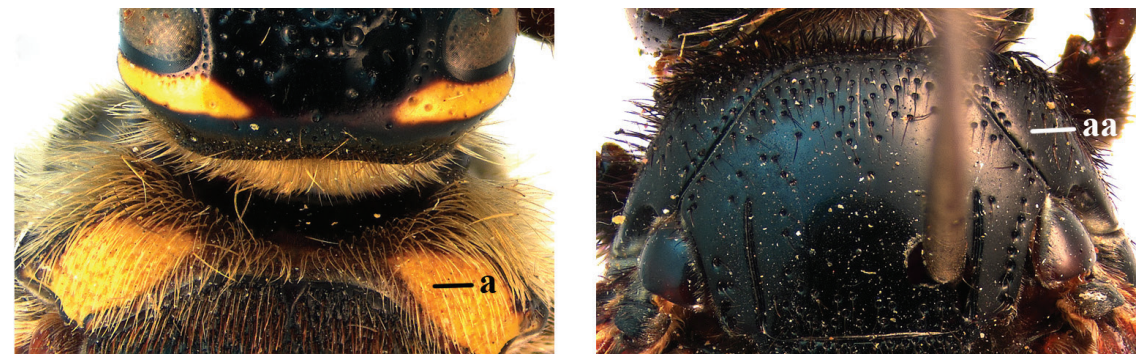

13 Middle of clypeus and anterior part of head above antenna sockets red; pronotum marked with red S. (D.) clypeata Sickman, 1894 Head black or only with yellow spots; pronotum marked with yellow....... 14 Mesonotum often evenly densely punctate (a); spiracular corner often smooth (b); pronotum posterodorsally widely smooth (c); scutellum and/or metanotum always with yellow bands (d)

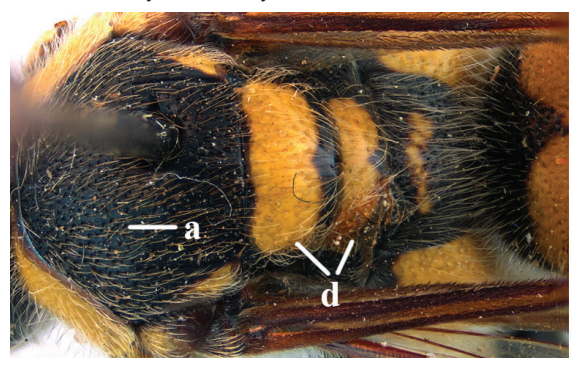
S. (D.) picteti de Saussure, 1855)

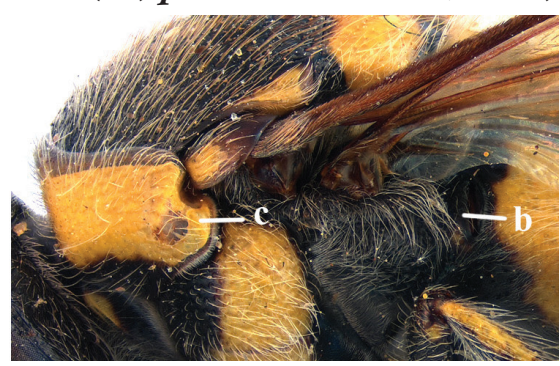

Mesonotum narrowly to largely impunctate medially; spiracular corner punctate, if smooth, then pronotum posterodorsally largely sculptured; pale pattern on scutellum and metanotum less developed

15 Area behind hind ocellus almost impunctate; gena with a yellow line behind

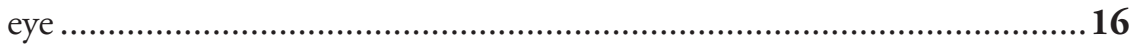

- $\quad$ Area behind hind ocellus with well-defined punctures; gena without yellow line

S. (D.) desidiosa Bingham, 1896

16 Scutellum black; anterior half of mesopleuron almost impunctate; apical fringe of T2-4 and S5 dark brown.............. S. (D.) taiwana Tsuneki, 1972 Scutellum largely yellow; anterior half of mesopleuron extensively closely punctate; apical fringe of T2 -4 and S5 pale golden

S. (D.) tigrimaculosa Yamane, 1995

17 Legs reddish (a); wings yellow hyaline, with dark tip (b); metasoma with reddish-brown setae throughout (c); T2-5 with yellow apical maculae (d) .... 
- $\quad$ Femora and tibiae black (aa); wings almost uniformly dark or yellow hyaline without dark tip (bb); metasoma setae not reddish-brown (cc); one to three tergites with yellow or reddish maculae $(\mathrm{dd})$.......
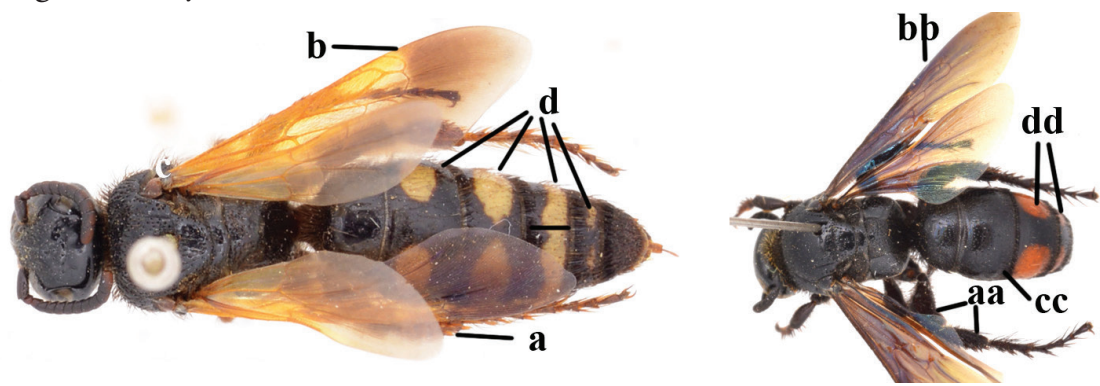

18 T3-T4 with pair of reddish spots (a); mesonotum and pronotum posterodorsally largely impunctate (b); dorso-lateral area of propodeum impunctate on its inner half (c) $[=$ S. quadripustulata auctt. from China $]$

S. (D.) binotata Fabricius, 1804

- $\quad$ T3 with yellow band and T4 black (aa); mesonotum and pronotum posterodorsally densely punctate $(\mathrm{bb})$ or largely impunctate; dorso-lateral area of propodeum more or less punctate (cc)
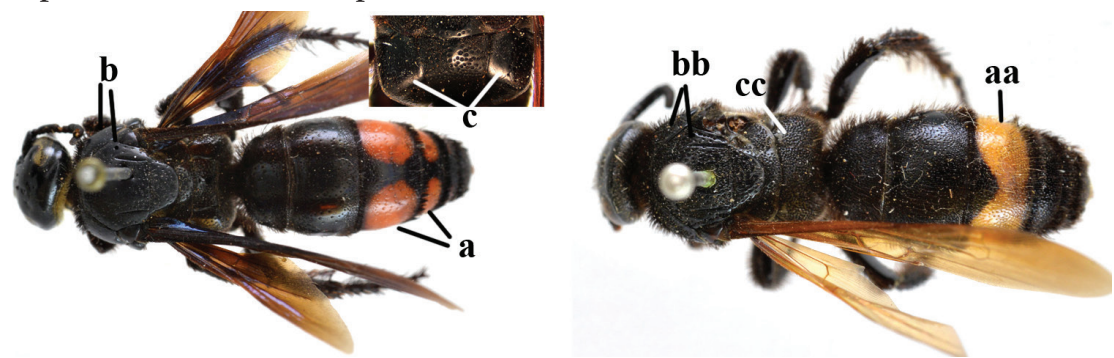

19 Mesonotum largely impunctate; frons and vertex impunctate; frons with transverse impressed line

20

- $\quad$ Mesonotum densely punctate (a); frons and vertex largely smooth (b) to densely punctate (bb); frons without transverse impressed line (c) ............21
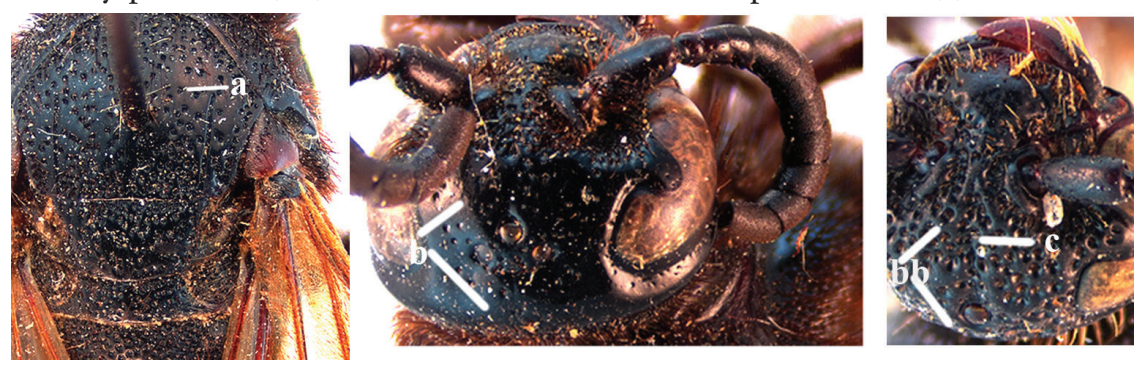

20 Transverse impressed line on frons slightly curved upwards laterally; intervals of punctures on posterior margin of pronotum broadly smooth and polished. S. (D.) apakaensis Tsuneki, 1972

- $\quad$ Transverse impressed line on frons straight; intervals of punctures on posterior margin of pronotum rugulose S. (D.) schrenckii Eversmann, 1846 
21 Head entirely black (a); median groove of frons more or less impressed (b) .... 22 Head partly red or yellow (aa); median groove of frons absent (bb)

S. (D.) watanabei (Matsumura, 1912)
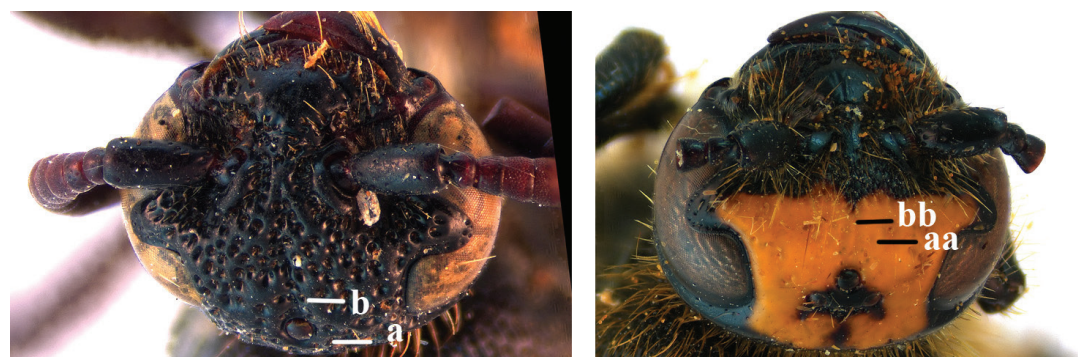

Vertex and frons with dense coarse punctation (a); median groove of frons distinct (b) S. (D.) formosicola Betrem, 1928

- Vertex and frons largely smooth, without large punctures, (aa); median groove of frons indistinct $(\mathrm{bb})$. S. (D.) oculata Matsumura, 1911
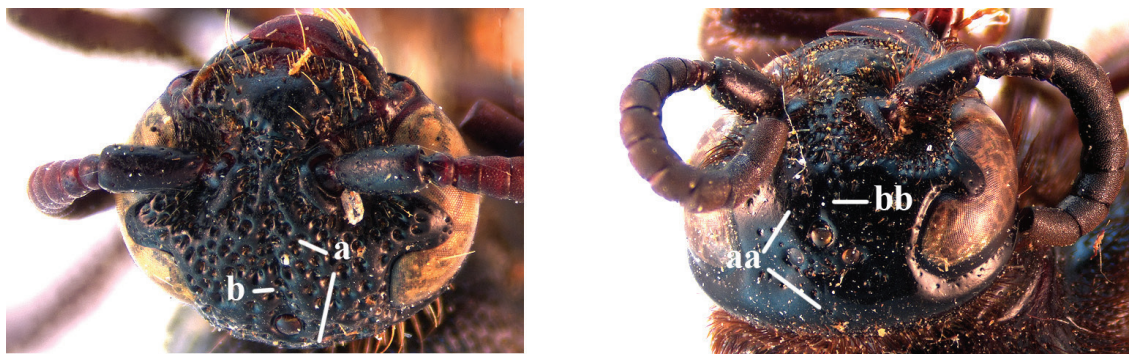

23 Metasoma entirely black (a) 24

Metasoma with variable whitish-yellow to reddish pattern (aa) 26
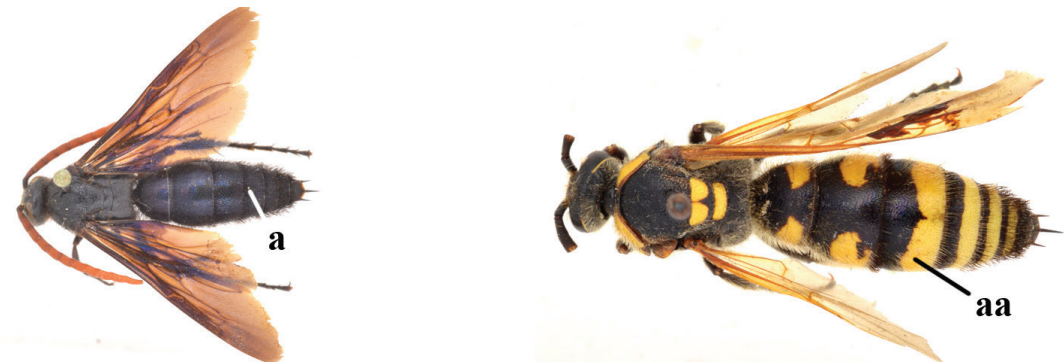

24 Antenna robust subapically, penultimate flagellomere $1.2 \times$ longer than wide (a); anterior ocellus in a broad deep pit (b) ....S. (D.) laeviceps Smith, 1855
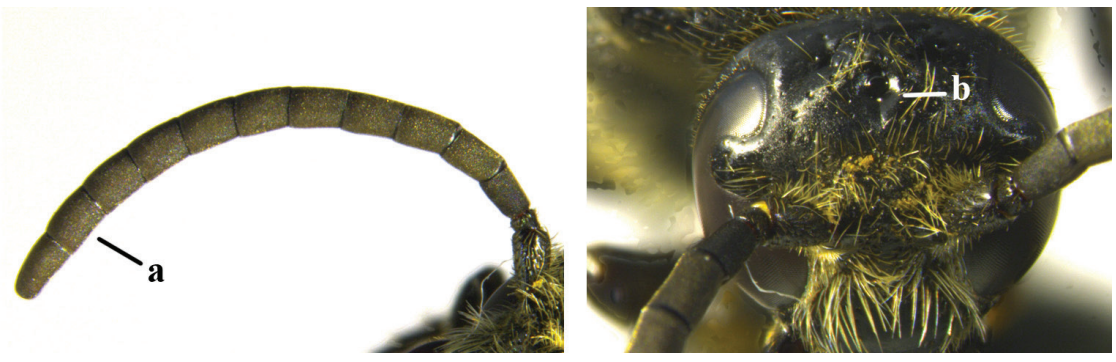
- $\quad$ Antenna slender subapically, penultimate flagellomere distinctly (1.6x) longer than wide (aa); anterior ocellus in a narrow pit (bb)
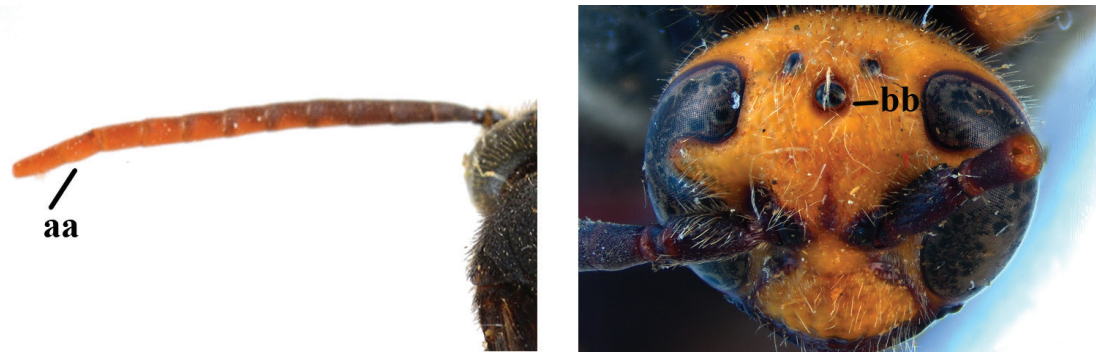

25 Vertex entirely black (a); setae of metasoma entirely black (b)

S. (D.) affinis Guérin-Méneville, 1845

Vertex partly to nearly entirely yellowish-red (aa); setae of metasoma yellowish, but black on T6-T7 (bb) S. (D.) superciliaris de Saussure, 1864
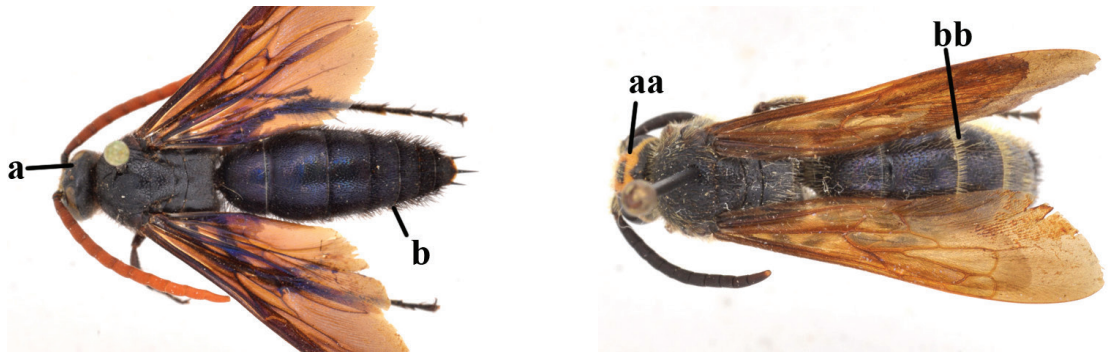

26 Head and mesosoma entirely black (a) 27

Head and/or mesosoma with variable yellow to reddish patterns (aa)
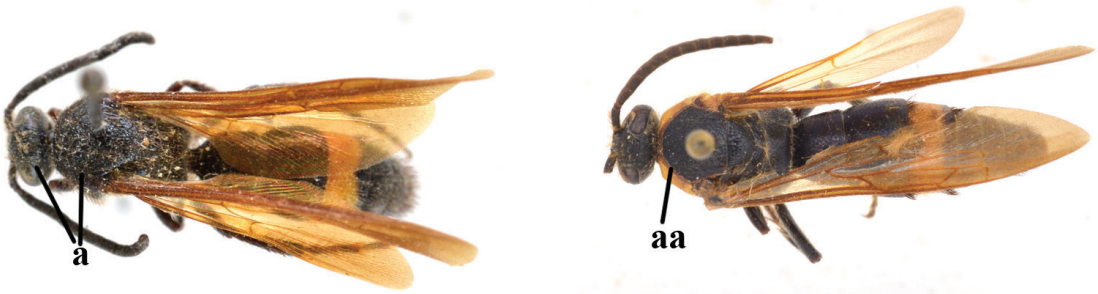

$27 \quad$ Femora and tibiae red; metasoma with reddish-brown setae, even on black parts; T2-T5 with yellow band S. (D.) rufispina Morawitz, 1889

- $\quad$ Femora and tibiae black; setae on metasoma not reddish-brown; often only T3 with yellow or reddish band 
28 Antenna shorter than head and mesosoma combined

Antenna longer than head and mesosoma combined (a)

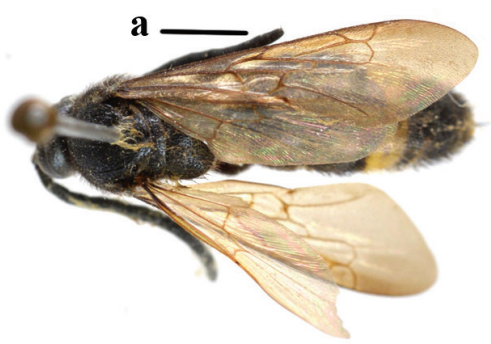

29 Wings not paler apically; mesoscutum narrowly impunctate medio-posteriorly S. (D.) apakaensis Tsuneki, 1972

- Wings slightly paler apically; mesoscutum broadly impunctate medio-posteriorly.

S. (D.) schrenckii Eversmann, 1846

30 Lateral areas of propodeum almost smooth (a); yellow band of T3 uninterrupted or indistinctly interrupted (b); metasoma $3.0 \times$ longer than wide (c)..

S. (D.) formosicola Betrem, 1928

- $\quad$ Lateral areas of propodeum distinctly punctate (aa); yellow band of T3 distinctly interrupted (bb); metasoma $2.4 \times$ longer than wide (cc).

S. (D.) oculata Matsumura, 1911
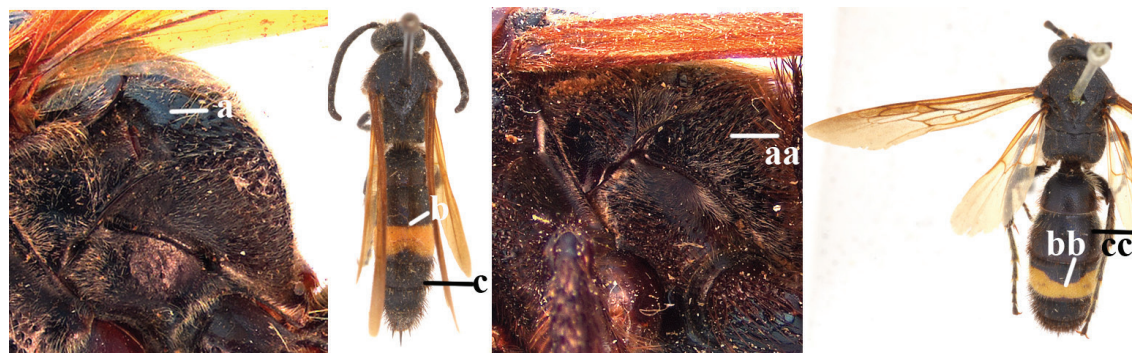

31 Dorso-median area of propodeum smooth to superficially and sparsely punctate (intervals at least as large as puncture diameter)

32

- Dorso-median area of propodeum more or less strongly and densely punctate (intervals smaller than puncture diameter) ..................................................34

32 Mesonotum and scutellum uniformly punctate (a); often only T3 with a more or less interrupted pale band (b) .....S. (D.) nobilis de Saussure, 1858

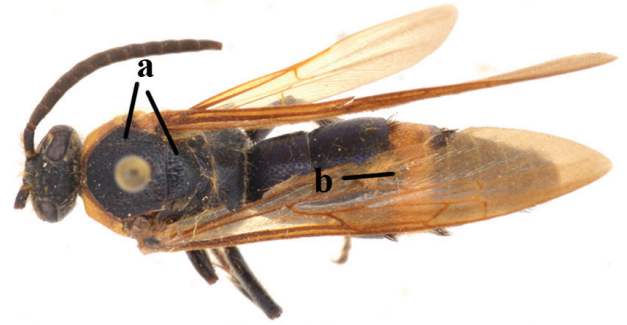


- $\quad$ Mesonotum and scutellum with impunctate area medio-posteriorly; tergites with variable pale pattern ............................................................33

33 T3-T5 each with a medially constricted broad band (rarely also T2 with a pair of yellow spots, yellow band on T5 sometimes greatly reduced or absent); punctures on mesosoma and propodeum (including lateral face) smaller and closer; wings brownish-yellow; punctures on metasoma smaller.

\section{S. (D.) wusheensis Tsuneki, 1972}

- $\quad$ Only T3 with two large yellow spots and T4-T5 black; punctures on mesosoma and propodeum (including lateral face) much coarser and slightly sparser; wings pale yellow; punctures on metasoma larger.....

\section{S. (D.) bnun Tsuneki, 1972}

34 Pronotum postero-dorsally yellow or red.

Pronotum postero-dorsally black

35 Body black and reddish (a): anterior part of head largely red; frontal spatium not separated from frons (b); frons with punctures as on frontal spatium, smooth laterally (c); median groove of frons indistinct (d); T1 densely punctate, posterior margin with extremely dense and fine punctures (e)

\section{S. (D.) clypeata Sickman, 1894}
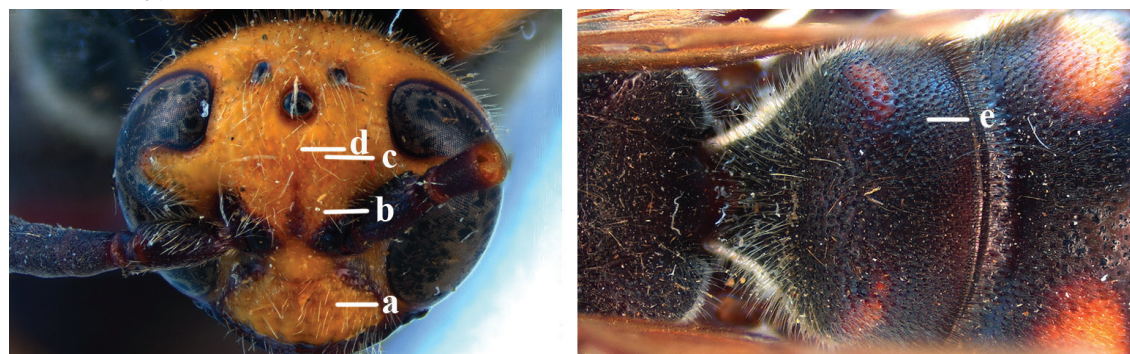

- $\quad$ Body black and yellow, head black or only with yellow spots (aa); frontal spatium usually separated from frons by a linear depression (bb), if not separated, then punctures on frons sparser than punctures on frontal spatium (cc); median groove of frons always distinct (dd); T1 usually sparsely punctate (ee)
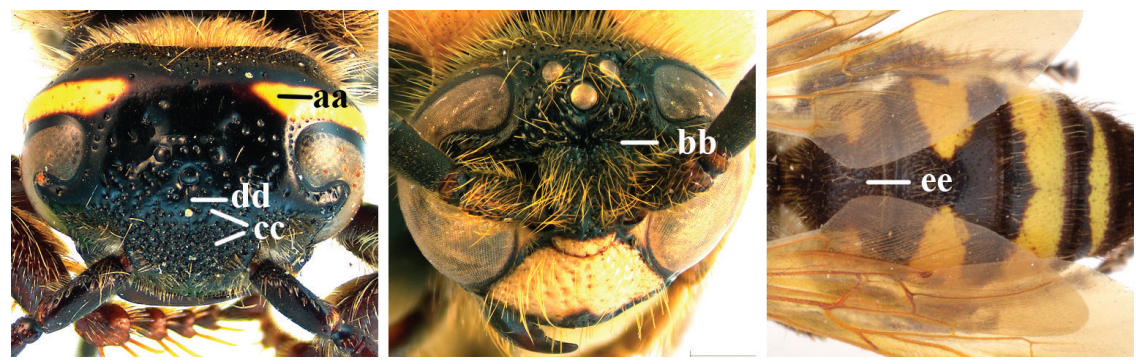
36 Three large yellow spots present on propodeum (a); spiracular corner punctate (b) S. (D.) desidiosa Bingham, 1896
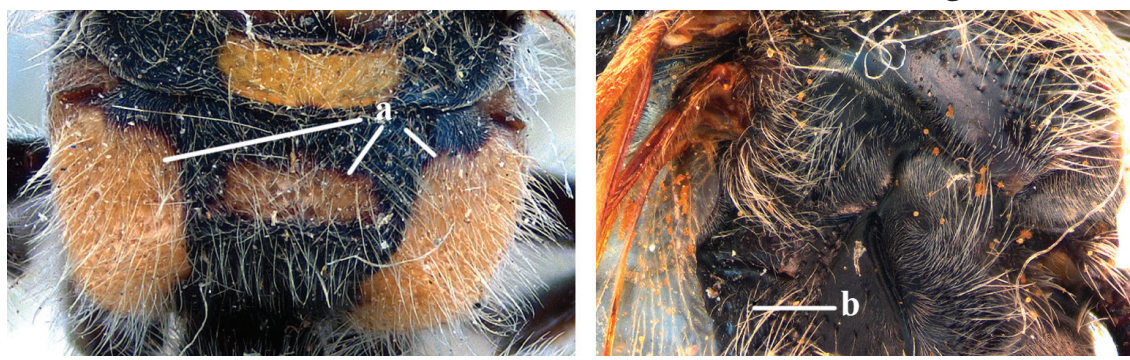

Propodeum entirely black (aa); spiracular corner smooth (bb) 37
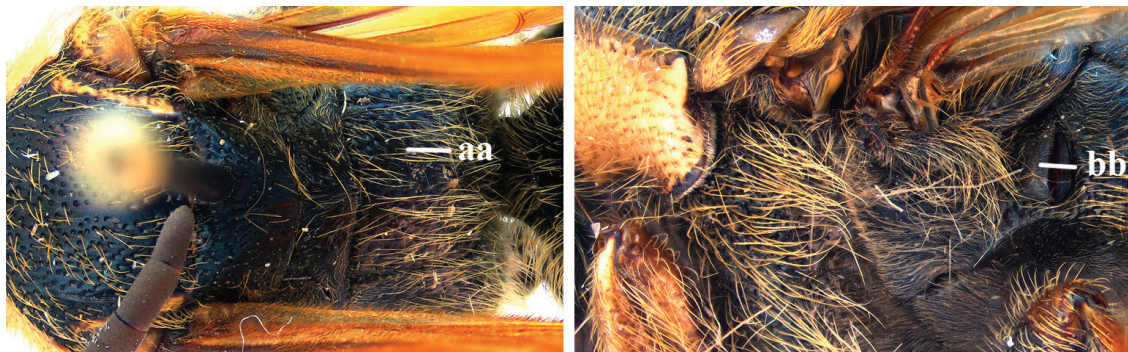

Mesonotum often evenly densely punctate (a); scutellum and/or metanotum always with yellow bands (b)

S. (D.) picteti de Saussure, 1855) Mesonotum narrowly to largely impunctate medially (aa); yellow pattern on scutellum and metanotum absent $(\mathrm{bb})$ or less developed.....

S. (D.) taiwana Tsuneki, 1972
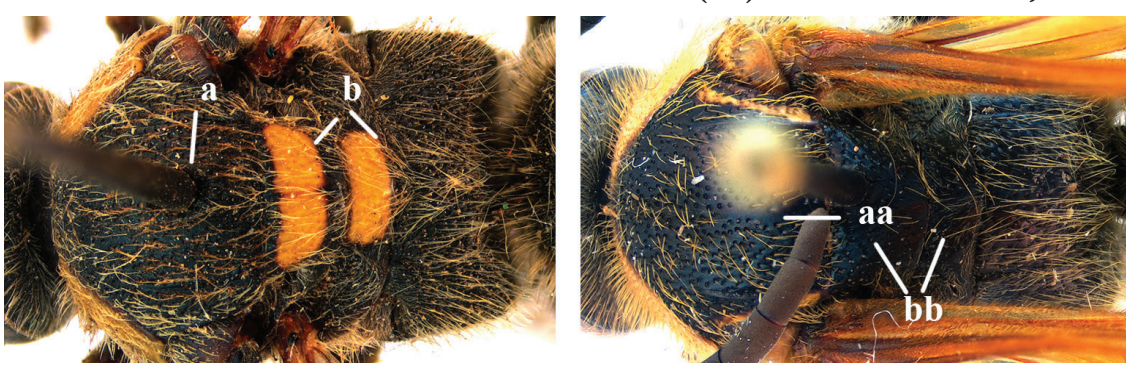

T3-T4 with paired reddish spots (a); flagellum somewhat widened towards apex (b).

S. (D.) binotata Fabricius, 1804

- $\quad$ T3 or T3-T4 with yellow bands (aa); flagellum not widened towards apex (bb) S. (D.) watanabei (Matsumura, 1912)
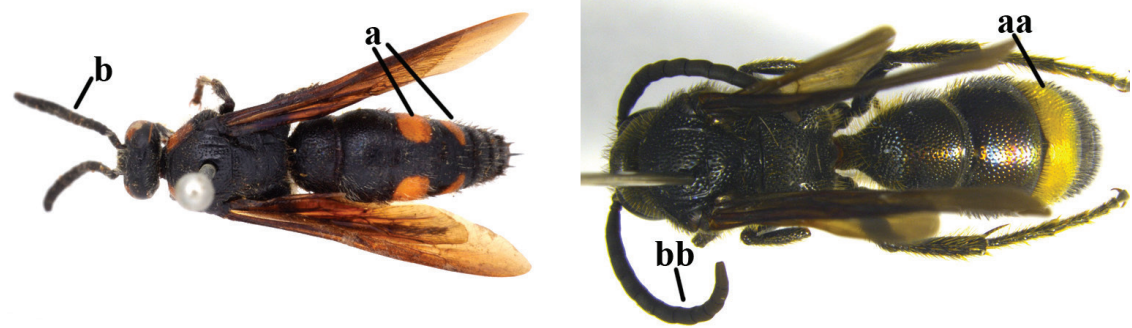
Notes. The name Scolia quadripustulata Fabricius was misapplied for a long time to another species now known as Scolia binotata Fabricius (Gupta and Jonathan 2003). We checked all specimens from China in IOZ and RMNH and all were found to belong to Scolia (Discolia) binotata Fabricius. All reported records of S. quadripustulata from China concern S. binotata; therefore, we delete $S$. quadripustulata from the Chinese fauna.

\section{Acknowledgements}

The first author is very grateful to Frederique Bakker, the manager of RMNH Hymenoptera Collection (Leiden) and to Hong Liu (IOZ, Beijing) for facilitating her visit for examining specimens. This research was supported by the Scientific Research Foundation for Doctors of Hunan University of Arts and Science (19BSQD30), Scientific Research Fund of Hunan Provincial Education Department (20K089) and Hunan Provincial Natural Science Foundation of China (2020JJ5392).

\section{References}

Argaman Q (1996) Generic synopsis of Scoliidae (Hymenoptera, Scolioidea). Annals Historico-Naturales Musei Nationalis Hungarici 88: 171-222.

Betrem JG (1927) Een nieuwe indeeling der Scoliiden. Tijdschrift voor Entomologie 70 (verslag): XCIII-XCVIII.

Betrem JG (1928) Monographie der Indo-Australischen Scoliiden mit zoogeographischen Betrachtungen. Treubia 9 (suppl.): 1-388.

Betrem JG (1932) De Scoliiden-fauna van Banka. Entomologische Berichten 9: 412-415.

Betrem JG (1933) Die Scoliiden der indoaustralischen and palaearktischen Region aus dem Staatlichen Museum für Tierkunde zu Dresden (Hym.). Stettiner Entomologische Zeitung 94: 236-263.

Betrem JG (1935) Beitrage zur Kenntnis der Palaarktischen Arten des genus Scolia. Tijdschrift voor Entomologie 78: 1-78.

Betrem JG (1937) The males of the Indo-Australian Campsomeris species with yellow metanotum (Hym., Scoliidae). The Proceedings of the Royal Entomological Society of London (B) 6(5): 91-96. https://doi.org/10.1111/j.1365-3113.1937.tb00305.x

Betrem JG (1941) Étude systematique des Scoliidae de Chine et leurs relations avec les autres groups de Scoliidae. Notes d'Entomologie Chinoise 8(4): 47-188.

Betrem JG (1947 [1945]) Analyse van enkele fauna:-elementen van de Maleische Scoliiden. Tijdschrift voor Entomologie 88: 409-416.

Betrem JG (1962) The taxon Trielis (Hymenoptera: Scoliidae) and its type. Entomological News 73: 146.

Betrem JG (1967) The natural groups of Campsomeriella Betr., 1941 (Hymenoptera: Scoliidae). Entomologische Berichten 27: 25-29.

Betrem JG, Bradley JC (1972) The African Campsomerinae (Hym., Scoliidae). Mono-grafieën van de Nederlandse Entomologische Vereniging 6: 1-326. 
Bingham CT (1896) On some Exotic Fossorial Hymenoptera in the Collection of the British Museum, with Descriptions of New Species and of a New Genus of the Pompilidæ. Zoological Journal of the Linnean Society 25(164): 422-445. https://doi. org/10.1111/0044-0124.00164-i1

Bingham CT (1897) The Fauna of British India, including Ceylon and Burma: Hymenoptera, 1 (Wasps and Bees). Taylor and Francis, London, 579 pp. https://doi.org/10.5962/bhl. title. 100738

Bradley JC (1950) The most primitive Scoliidae. Eos (tomo extraord.): 427-437.

Bradley JC (1959) The Scoliidae of Africa. Annals of the Transvaal Museum 23: 331-362.

Bradley JC (1964a) The Fabrician types of Scoliidae (Hymenoptera), with notes and an appendix by J.G. Betrem. Spolia Zoologica Musei Hauniensis 21: 1-38.

Bradley JC (1964b) The type-specimens of the Scoliidae described by Amédée Lepeletier, Comte de Saint-Fargeau (with notes by J. G. Betrem) and by the Marchese Massimiliano Spinola. Estratto Dagli Annali Del Museo Civico Di Storia Naturale Di Genova 75: 16-196.

Bradley JC (1972) Scoliid types in the Museum für Naturkunde of the Humboldtuniversität zu Berlin. Zoologisches Museum und Institut für Spezielle Zoologie (Berlin) 48(1): 3-19. https://doi.org/10.1002/mmnz.19720480102

Bradley JC (1973) The scoliid types of Guérin-Méneville (Insecta: Hymenoptera: Scoliidae). Bulletin du Muséum National D’Histoire Naturelle (3) 112, Zoologie 86: 217-221.

Bradley JC (1974) The types of Scoliidae (Hymenoptera) described by Henri de Saussure or by Jules Sichel, or by them jointly. Revue Suisse Zoologie 81(2): 417-485. https://doi. org/10.5962/bhl.part.76015

Bradley JC, Betrem JG (1966) Burmeister's work on Scoliidae, with especial reference to types and synonymy (Hymenoptera: Scoliidae). Beiträge zur Entomologie 16: 73-84.

Bradley JC, Betrem JG (1967) The types of Scoliidae described by Frederick Smith (Hymenoptera). Bulletin of the British Museum (Natural History) Entomology 20 (7): 287-327.

Bradley JC, Betrem JG (1968) Friedrich Klugs material of Scoliidae with especial reference to his type specimens. Deutsche Entomologische Zeitschrift 15: 321-334. https://doi. org/10.1002/mmnd.4810150406

Day MC, George RE, David M (1981) The most primitive Scoliidae (Hymenoptera). Journal of Natural History 15: 671-684. https://doi.org/10.1080/00222938100770471

Elliott MG (2011) Annotated catalogue of the Australian Scoliidae (Hymenoptera). Technical Reports of the Australian Museum, Online, 22: 1-17. https://doi.org/10.3853 /j.1835-4211.22.2011.1562

Eversmann E (1846) Hymenoptorum rossicorum species novae vel parum cognitae. Bulletin de la Société Impériale des Naturalistes de Moscou XXII (2): 441-442.

Eversmann E (1849) Fauna hymenopterologica Volgo-Uralensis III. Idem XXII (2): 430.

Gupta SK, Jonathan JK (2003) Fauna of India and the adjacent countries, Hymenoptera: Scoliidae. Zoological Survey of India, Kolkata, 277 pp.

He JH, Chen XX, Fan JJ, Li Q, Liu CM, Lou XM, Xu ZF (2004) Hymenopteran Insect Fauna of Zhejiang. Science Press, Beijing, 1373: 354-816.

Hua LZ (2006) List of Chinese Insects, Vol. IV. Sun Yat-sen University Press, Guangzhou, 540 pp. Illingworth JF (1919) Monthly notes on grubs and other cane pests. Queensland Bur. BSES Division of Entomology Bulletins 7: 1-29. 
Illingworth JF (1921) Natural enemies of sugar-cane beetles in Queensland. Bur. BSES Division of Entomology Bulletins 13: 1-47.

Jonathan JK (1976) Records of additional Campsomerinae from India (Hymenoptera: Aculeata). Newsletter of the Zoological Survey of India, Calcutta 2 (3): 112-114.

Kim JK (2009) Taxonomic review of the tribe Campsomerini (Scoliinae, Scoliidae, Hymenoptera) in Korea. Animal Systematics, Evolution and Diversity 25(1): 99-106. https://doi. org/10.5635/KJSZ.2009.25.1.099

Krombein KV (1978) Biosystematic studies of Ceylonese Wasps, II: A monograph of the Scoliidae (Hymenoptera: Scolioidea). Smithsonian Contributions to Zoology 283: 1-56. https://doi.org/10.5479/si.00810282.283

Krombein KV (1979) Superfamily Scolioidea. In: Krombein KV, Hurd Jr PD, Smith DR, Burks BD (Eds) Catalog of Hymenoptera in America North of Mexico. Smithsonian Institution Press, Washington, DC, 1253-1321.

Kumar PG, Rajmohana K (2017) Checklist of Scoliidae (Insecta: Hymenoptera: Vespoidea) of India. Zoological Survey of India: 1-9.

Lelej AS, Mokrousov MV (2017) The types of Scoliidae (Hymenoptera), described by Eduard Eversmann, with some taxonomic notes and checklist of Russian Scoliidae. Far eastern Entomologist 340: 1-17. https://doi.org/10.25221/fee.340.1

Lepeletier A (1845) Historie naturelle des insects. Hyménoptères 3: 1-646.

Liu Z, van Achterberg C, He JH, Chen XX (submitted) Checklist of Scoliidae (Insecta: Hymenoptera: Scolioidea) from China.

Matsumoto R, Hasegawa M, Ichikawa A (2019) Scolia watanabei, an adventive wasp newly discovered in Japan (Hymenoptera, Scoliidae, Scoliinae). Bulletin of the Osaka Museum of Natural History 73: 1-5.

Micha I (1927) Beitrag zur Kenntnis der Scoliiden (Hym. Acul.) (Liacos Guer., Diliacos Sauss. Sich. und Triscolia Sauss. Sich). Mitteilungen aus dem Zoologischen Museum in Berlin 13(1): 1-156.

Morawitz F (1889) Insecta, a Cl. G. N. Potanin in China et in Mongolia novissime lecta. IV. Hymenoptera Aculeata. Horae Societatis Entomologicae 23: 112-168.

Okamoto H (1924) The insect fauna of Quelpart Island. Bulletin of the Agricultural Experimental Station of the Government-General of Chosen 1: 1-233.

Osten T (2000) Die Scoliiden des Mittelmeer-Gebietes und angrenzender Regionen (Hymenoptera). Ein Bestimmungsschlüssel. Linzer Biologische Btrge 32(2): 537-593.

Osten T (2005) Checkliste der Dolchwespen der Welt (Insecta: Hymenoptera, Scoliidae). Naturforschende Gesellschaft 220: 1-62.

Osten T, Arens W (2004) Beitrag zur Kenntnis der Scoliiden-Fauna Griechenlands (ohne Zypern) (Hymenoptera, Scoliidae). Entomofauna 25(20): 305-320.

Ozbek H, Anlas S (2011) Distribution of Scoliidae (Hymenoptera: Aculeata) of Turkey with their zoogeographic characterization. Turkish Journal of Entomology 35(4): 627-639.

Prosvirov AS, Savitsky VY (2011) On the significance of genital characters in supraspecific systematics of the elaterid subfamily Agrypninae (Coleoptera, Elateridae). Entomological Review 91(6): e755. https://doi.org/10.1134/S0013873811060091

Samin N, Bağrıaçık N (2012) A contribution to the knowledge of Scoliidae (Hymenoptera) from Iran. Entomofauna 33(27): 389-396. 
Samin N, Bağrıaçık N, Gadallah NS (2014) A checklist of Iranian Scoliidae (Hymenoptera: Vespoidea). Munis Entomology \& Zoology 9(2): 713-723.

Saussure H de (1858) Description de diverses especes nouvelles ou peu connues du genre Scolia. Annales de la Societé entomologique de France 3(6): 193-249.

Saussure H de, Sichel J (1864) Catalogue des espèces de l'ancien genre Scolia, contenant les diagnoses, les descriptions et la synonymie des espèces, avec des remarques explicatives et critiques. Geneve et Paris, V. Mason, 350 pp. https://doi.org/10.5962/bhl.title.9323

Schulten GGM, Feijen HR, Feijen C (2011) The genus Bellimeris Betrem (Hymenoptera: Scoliidae, Campsomerinae). Zoologische Mededelingen 85: 887-903.

Smith F (1855) Mutillidae and Pompilidae. In: Catalogue of the Hymenopterous Insects in the collection of the British Museum. Taylor and Francis, London, 1-206.

Tsuneki K (1972a) Studies on the scoliid wasps of eastern Asia (Hymenoptera). Etizenia 62: 1-41.

Tsuneki K (1972b) Some scoliid wasps from South East Asia (Hymenoptera). Etizenia 63: 1-9.

Turner RE (1911) Further notes on the Thynnidae and Scoliidae: Notes on fossorial Hymenoptera V. Annals and Magazine of Natural History (8)8: 602-624. https://doi. org/10.1080/00222931108693069

Uchida T (1933) Revision der Japanischen Scoliiden mit Beschreibungen der neuen Arten und Formen. Journal of the Faculty of Agriculture, Hokkaido Imperial University 32: 229-262. Uchida T (1936) Fauna Nipponica. 10(9/1) Family Scoliidae. Sanseido, Tokyo, 72 pp. [in Japanese] van Achterberg C (1979) A revision of the subfamily Zelinae auct. (Hymenoptera, Braconidae). Tijdschrift voor Entomologie 122: 241-479.

Yasumatsu K (1946) Hymenoptera aculeata collected by Mr. K. Tsuneki in North China and Inner Mongolia 11. Vespoidea 1. Mushi 17(4): 13-14. 